\title{
Cholesterol Metabolism: A Review of How Ageing Disrupts the Biological Mechanisms Responsible for its Regulation
}

5 A. E. Morgan ${ }^{a}$, K. M. Mooney ${ }^{b}$, S. J. Wilkinson ${ }^{a}$, N. A. Pickles ${ }^{c}$, and M. T. Mc Auley ${ }^{a}$ 6

${ }^{a}$ Department of Chemical Engineering, University of Chester, Thornton Science Park, Chester, CH2 4NU

${ }^{b}$ Faculty of Health and Social Care, Edge Hill University, Ormskirk, Lancashire, L39 4QP

${ }^{c}$ Department of Biological Sciences, University of Chester, Parkgate Road, Chester, CH1 4BJ

\begin{abstract}
Cholesterol plays a vital role in the human body as a precursor of steroid hormones and bile acids, in addition to providing structure to cell membranes. Whole body cholesterol metabolism is maintained by a highly coordinated balancing act between cholesterol ingestion, synthesis, absorption, and excretion. The aim of this review is to discuss how ageing interacts with these processes. Firstly, we will present an overview of cholesterol metabolism. Following this, we discuss how the biological mechanisms which underpin cholesterol metabolism are effected by ageing. Included in this discussion are lipoprotein dynamics, cholesterol absorption/synthesis and the enterohepatic circulation/synthesis of bile acids. Moreover, we discuss the role of oxidative stress in the pathological progression of atherosclerosis and also discuss how cholesterol biosynthesis is effected by both the mammalian target of rapamycin and sirtuin pathways. Next, we examine how diet and alterations to the gut microbiome can be used to mitigate the impact ageing has on cholesterol metabolism. We conclude by discussing how mathematical models of cholesterol metabolism can be used to identify therapeutic interventions.
\end{abstract}

\section{Keywords}

Cholesterol, ageing, longevity, low density lipoprotein cholesterol (LDL-C), high density lipoprotein cholesterol (HDL-C), microbiome 


\subsection{Introduction}

An intriguing feature of ageing, is that it is often accompanied by the dysregulation of whole body cholesterol metabolism (Mc Auley and Mooney, 2014). A clinical manifestation of this process is an age-related rise in the plasma levels of low density lipoprotein cholesterol (LDL-C) (Abbott et al., 1983). This rise in LDL-C has a significant impact on cardiovascular disease (CVD) risk, due to the association elevated plasma LDL-C has with the mechanisms which underpin atherosclerotic plaque formation (Gould et al., 2007). Conversely, prospective studies have shown that high density lipoprotein (HDL) levels diminish with age (Wilson et al., 1994). This is clinically significant, as HDLs are central to reverse cholesterol transport (RCT) (Groen et al., 2004). This process, which results in the trafficking of HDL-C, or the so-called 'good cholesterol' to the liver for subsequent removal via the intestine, represents the only way of eliminating excess cholesterol from peripheral tissue. There is a plethora of epidemiological evidence supporting an inverse relationship between $\mathrm{HDL}-\mathrm{C}$ levels and CVD risk, and evidence has consistently shown that HDL-C levels are correlated with longevity in several population groups (Ferrara et al., 1997). It is therefore not surprising, that a healthy ageing phenotype has regularly been associated with the fine tuning of cholesterol metabolism, within certain cohorts of individuals who possess particular genetic variants in tandem with exceptional longevity (Milman et al., 2014). For example, a three-fold increase in the prevalence of homozygosity for the favourable $1405 \mathrm{~V}$ polymorphism, a mutation in the cholesteryl ester transfer protein (CETP), a key enzyme involved in RCT has been observed in those exhibiting exceptional longevity (Barzilai et al., 2003). Individuals with the $1405 \mathrm{~V}$ genotype have significantly larger HDL and LDL particle sizes, leading to the suggestion, that the risk of atherosclerosis development is diminished as a result of the diminished ability of the LDL particle to cross the arterial endothelium (Barzilai et al., 2003; Kulanuwat et al., 2015).

Many key mechanisms involved in cholesterol metabolism are affected by ageing (Figure 1). For instance, ageing has been associated with a decline in the hepatic expression of cholesterol 7-alphahydroxylase (CYP7AI), a key regulator of bile acid synthesis, thus resulting in a decreased cholesterol demand for conversion to bile acids (Bertolotti et al., 2007). Furthermore, there is a decline in hepatic LDL receptors (LDLr) with age, leading to a reduction in LDL-C clearance (Ericsson et al., 1991; Millar et al., 1995). Within the small intestine, there is an increase in the number of the sterol transporter Niemann-pick C1-like 1 (NPC1L1), a key mediator of cholesterol absorption (Duan et al., 2006). In addition, there is a decline in the predominant bacterial populations that play a role in the enterohepatic circulation of bile acids (Hopkins and Macfarlane, 2002). Moreover, dysregulation of cholesterol biosynthesis is associated with two key intracellular pathways which are thought to underpin intrinsic ageing and health-span. These pathways are defined by the mammalian/mechanistic target of rapamycin (mTOR) and by the NAD+-dependent deacetylase silent information regulator proteins (sirtuins). The former of these pathways has been suggested as a central regulator of intracellular cholesterol homeostasis (Wang et al., 2011), while mammalian sirtuin 6 (Sirt6), has been identified as a critical controller of sterol-regulatory element binding protein (SREBP)-2 in rodents (Tao et al., 2013). These recent findings suggest that it is not one mechanism that is the central driver of cholesterol dysregulation with age, but rather a number of mechanisms interacting with one another to disrupt cholesterol metabolism. Therefore, it is important to view cholesterol metabolism and its relationship with ageing in an integrated way. In this review we will 1) discuss in depth how ageing impacts cholesterol metabolism, 2) discuss a 
number of the genes involved in cholesterol metabolism which have been implicated with longevity, 3) discuss the role of oxidative stress in disrupting cholesterol metabolism, 4) describe the role of caloric restriction (CR) in modulating cholesterol metabolism, 5) describe recent evidence that demonstrates the role mTOR and sirtuins play in cholesterol biosynthesis, 6) provide an overview of diet and its impact on cholesterol metabolism, 7) discuss the interactions between cholesterol metabolism and the gut microbiome, 8) propose therapeutic strategies based around the gut microbiome which could help to prevent the dysregulation of cholesterol metabolism with age, and lastly we will provide an overview of mathematical models that have been used to gain an increased insight into the dynamics of cholesterol metabolism.

\subsection{Overview of Cholesterol Metabolism}

Cholesterol plays a vital role in the human body, as it is an essential component of all cell membranes. In addition, it is the precursor of steroid hormones, which control a range of physiological functions. Cholesterol is also the precursor to bile acids, which are necessary for the intestinal absorption of cholesterol, fats and lipophilic vitamins. Cholesterol can be obtained from the diet as well as being endogenously synthesised, the latter being the main source in humans (Gylling, 2004). A subtle balancing act between ingestion, absorption, synthesis and excretion maintains whole body cholesterol metabolism (Figure 1). Briefly, 1) the average daily intake of cholesterol is 304 and $213 \mathrm{mg} /$ day, for males and females respectively, living in the UK (Henderson et al., 2003). Of this, $85-90 \%$ is free cholesterol while $10-15 \%$ is in the esterified form (Iqbal and Hussain, 2009). Ingested cholesterol then enters the small intestine, where absorption occurs (Tancharoenrat et al., 2014). 2) Cholesterol in the free form is more readily incorporated into a bile acid micelle for absorption. Therefore, cholesterol ester hydrolase (CEH) converts the esterified cholesterol into free cholesterol, which can then be incorporated into a bile acid micelle (Ikeda et al., 2002). This enables NPC1L1 to absorb the cholesterol by clathrin-mediated endocytosis (Betters and Yu, 2010). Upon entry to the enterocyte, acetyl CoA acetyltransferase 2 (ACAT2) converts the cholesterol into the esterified form in order to maintain the concentration gradient (Chang et al., 2009). Microsomal triglyceride transfer protein (MTP) then shuttles the esterified cholesterol with apo B-48, while triacylglycerol and phospholipids are also incorporated to form a chylomicron (Jamil et al., 1995). 3) The chylomicron is then exported to the lymphatic system via exocytosis, and enters the blood stream, where it can deliver fatty acids to the tissues before being removed by hepatic remnant receptors and degraded in the liver (Cooper, 1997). 4) Cholesterol is also synthesised endogenously in all nucleated cells in the body, including the hepatocytes and enterocytes from acetyl CoA (Bloch, 1965). 5) From the hepatic cholesterol pool, very low density lipoprotein cholesterol (VLDL-C) is formed, to enable the transport of endogenously synthesised triacylglycerol to the tissues. Partial hydrolysis of VLDL-C by lipoprotein lipase (LPL) forms the LDL-C precursor, intermediate density lipoprotein cholesterol (IDL-C). IDL-C is further hydrolysed by hepatic lipase to form LDL-C (Havel, 1984). 6) Following this, VLDL-C, IDL-C and LDL-C are removed from the circulation by hepatic LDLr (Veniant et al., 1998). In addition, LDL-C can also be absorbed by receptor independent means (Spady et al., 1985). 7) Accumulation of LDL-C can develop into atherosclerosis the major clinical manifestation of CVD (Baigent et al., 2010). 8) Cholesterol can be removed from the tissues by HDL in RCT, via receptors including ATP-binding cassette subfamily A member 1 (ABCA1), and scavenger receptor class $B$ member 1 (SRB1), or independently. CETP then acts to facilitate the 1:1 exchange of cholesterol from HDL-C for triacylglycerol from VLDL-C and LDL-C 
(Ohashi et al., 2005). 9) Cholesterol can be removed from the body by two mechanisms, as cholesterol can be removed directly via the ATP-binding cassette subfamily G5/G8 (ABCG5/G8) receptor and effluxed to the gall bladder (Repa et al., 2002) or alternatively, cholesterol can be converted to bile acids for faecal excretion. Bile acids are usually conjugated to glycine or taurine (3:1) before being effluxed to the gallbladder by receptors, including bile salt export pumps (BSEP) (Soroka and Boyer, 2014) for release into the small intestine postprandially in response to cholecystokinin (CKK) (Marciani et al., 2013). 10) On average, $500 \mathrm{mg} /$ day of both cholesterol and bile acids are excreted (Lu et al., 2010). Of the $5 \%$ of circulating bile acids that are excreted daily, $98 \%$ are in the unconjugated form due to a lower reabsorption efficiency in the ileum (Batta et al., 1999; Gérard, 2014). Conjugated bile acids are deconjugated by bacterial modification (Joyce et al., 2014). Bacterial species such as Lactobacillus and Bifidobacterium produce bile acid hydrolase (BSH) in order to remove the associated amino acid (Oner et al., 2014). There are several survivalpromoting motives for bacteria to respond in this way; these include providing a nutrition source and bile acid detoxification (Begley et al., 2006). This modulation of bile acid circulation indicates that the gut microbiome also plays an important role in maintaining cholesterol metabolism. Collectively the mechanisms we have discussed coordinate together to maintain whole body cholesterol balance and age-related changes to such mechanisms have important implications for health.

\subsection{Impact of Ageing on Cholesterol Metabolism}

\subsection{Lipoprotein Dynamics and Ageing}

It is well established that LDL-C levels rise with age (Abbott et al., 1983). Evidence from the Framingham Study demonstrates LDL-C steadily rises from 97.08 and $100.44 \mathrm{mg} / \mathrm{dL}$ in $15-19$ year olds, to 132.25 and $156.91 \mathrm{mg} / \mathrm{dL}$ in $75-79$ year olds in males and females, respectively (Abbott et al., 1983). An increase in LDL-C is correlated with an increased risk of CVD; every $1 \mathrm{mmol} / \mathrm{L}$ of LDL-C is associated with a $28 \%$ increased risk of coronary heart disease (CHD)-mortality (Gould et al., 2007). Paradoxically, this is not always the case, as higher levels of LDL-C was associated with a lower risk of all causes of mortality in a Chinese cohort of $935 \geq 80$ year old males and females. In this cohort each $1 \mathrm{mmol} / \mathrm{L}$ increase in LDL-C reflected a 19\% decrease in mortality (Lv et al., 2015). Furthermore, abnormally high LDL-C ( $\geq 3.37 \mathrm{mmol})$ resulted in a $40 \%$ reduction in mortality risk. Participants that survived the three year survey-based study were also found to have a higher prevalence $(39.0 \%$ vs. 27.7\%) of central obesity (Lv et al., 2015). This phenomenon in the oldest old could be explained by several factors. Firstly, it is possible that individuals susceptible to the effects of increased LDL-C levels had already died before the age of 80 years, and are consequently not included in studies of the oldest old. It has also been suggested increased LDL-C enhances the immune response to pathogens (Biswas et al., 2015; Netea et al., 1996).

A mechanistic explanation for the correlation between advancing age and increased LDL-C is that over time there is a reduction in its rate of clearance from the circulation. Under normal circumstances, apo B-100 containing lipoproteins, LDL-C and VLDL-C, are removed from the circulation by hepatic LDLr (Veniant et al., 1998). From the hepatic pool, cholesterol can be directly effluxed to the small intestine for excretion, or first be converted to bile acids. This process occurs in order to maintain the levels of circulating cholesterol, by counteracting the synthesis and ingestion 
of cholesterol. Deficiency in LDLr results in severe hypercholesterolaemia (type II), as cholesterol cannot be removed from the plasma and into the liver for excretion (Hasan et al., 2014; Kowala et al., 2000). Murine models have shown LDLr deficiency increases the residence time of LDL-C and VLDL-C by decreasing the clearance rate (Ishibashi et al., 1993). For example, Ishibashi et al. (1993) demonstrated LDLr deficiency increased the half-life of ${ }^{125}$ I-LDL and ${ }^{125}$ I-VLDL by 2.5 - and 30 -fold respectively, while the half-life of ${ }^{125} \mathrm{I}$-HDL was unaffected. Furthermore, LDLr deficiency induced a $2-$ fold increase in total cholesterol, a 7- and 9-fold increase in IDL-C, and LDL-C respectively, in addition to a modest 1.3-fold rise in HDL-C (Ishibashi et al., 1993). In humans the number of hepatic LDLr decrease with age, thus reducing the rate of LDL-C clearance, and augmenting LDL-C residence time (Millar et al., 1995). Furthermore, the rate of VLDL apo B-100 synthesis increases (Millar et al., 1995). This age-related decline in LDLr is possibly a contributing factor to LDL-C accumulation. It is likely there are several factors influencing the decline in LDLr with age, the primary factor being the decline in the rate of bile acid synthesis, as discussed in section 3.2. Briefly, a decline in bile acid synthesis, results in a decline in cholesterol utilisation from the hepatic pool. Thus, less cholesterol is required to maintain the hepatic pool, resulting in down regulation of LDLr and plasma cholesterol accumulation. More recently, proprotein convertase subtilisin kexin-9 (PSCK9) has also been associated with LDLr degradation. PCSK9, regulated by SREBP-2, acts by binding to the epidermal growth factor like repeat A domain of LDLr leading to receptor degradation. Levels of PCSK9 have been shown to rise with age, and may account for the age-related reduction in LDLr and LDL-C clearance (Cui et al., 2010; Dubuc et al., 2010).

HDL-C levels are also affected by the ageing process (Wilson et al., 1994). Typically, HDL-C is observed to decrease by $1 \%$ per year (Ferrara et al., 1997). The age-related decline of the atheroprotective HDL-C is linked with the pathogenesis of CVD (Cooney et al., 2009). For instance, a favourable HDL-C profile is often observed in the offspring of centenarians (Barzilai et al., 2001). Due to the lack of controls, to compare the lipoprotein protein of long lived individuals with age-matched controls, offspring studies are utilised. By using this approach, inherited elevated HDL-C levels can be observed (Barzilai et al., 2001). Therefore, increased levels of HDL-C have been highlighted as a potential mechanism conferring exceptional longevity. This is substantiated by evidence detailing individuals with familial hyperalphalipoproteinaemia, whereby the production rate of apo A-I is markedly increased. These individuals display increased HDL-C levels, and exhibit reduced rates of CHD, which may play a role in promoting exceptional longevity (Rader et al., 1993).

\subsection{Cholesterol Absorption and the Synthesis and Enterohepatic Circulation of Bile Acids}

Cholesterol from both the diet and bile is absorbed in the small intestine (Repa et al., 2002; Tancharoenrat et al., 2014). Cholesterol absorption is regulated by two receptors on the apical membrane, NPC1L1 and ABCG5/G8. NPC1L1 is predominantly located in the jejunum, although this is found the length of the small intestine, and is responsible for the absorption of sterols from the intestinal lumen into the enterocytes (Masson et al., 2010; Sane et al., 2006). ABCG5/G8 is located primarily in the jejunum and ileum and to a lesser extent, the duodenum, and is responsible for the efflux of non-cholesterol sterols from the enterocyte into the intestinal lumen (Masson et al., 2010; Wang et al., 2007). Murine models have demonstrated that NPC1L1 expression significantly increases in the duodenum and jejunum with age, while ABCG5/G8 expression is suppressed. These age-related changes to receptor expression represented a $19-40 \%$ increase in cholesterol absorption 
between young adult and aged adult mice. This effect was amplified in response to high levels of oestrogen (Duan et al., 2006). These findings are intriguing, as it has long been suggested that an increase in cholesterol absorption is an important factor in the rise in LDL-C which accompanies ageing (Hollander and Morgan, 1979).

Bile acid synthesis declines with age in humans (Bertolotti et al., 2007; Einarsson et al., 1985). This is due to a reduction in the hepatic expression of the rate limiting enzyme for bile acid synthesis, CYP7Al (Bertolotti et al., 2007). This in turn reduces cholesterol utilisation, which is accompanied by a rise in plasma cholesterol (Uchida et al., 1996). Significantly, it has been estimated that with every 10 years, there is a decrease of $60 \mathrm{mg} /$ day in cholesterol converted to bile acids (Bertolotti et al., 1993). Thus, a decline in bile acid synthesis is another factor which could contribute to the dysregulation of whole body cholesterol metabolism with age.

In rodents a mechanistic explanation for the decline in CYP7AI activity has been postulated. It is suggested the reduction in its activity is in part, due to neuroendocrine dysfunction which causes an age dependent decrease in growth hormone, which is known to act pleiotropically on lipoprotein metabolism (Parini et al., 1999). Synthesised bile acids are effluxed from the liver primarily by BSEP, and stored in the gall bladder, with BSEP expression remaining fairly consistent with age in mice (Fu et al., 2012). Following release into the small intestine postprandially, bile acids aid in the absorption of dietary lipids, and undergo bacterial modification before being reabsorbed or excreted. Therefore, any age related alterations to these processes will have consequences for whole body cholesterol metabolism.

Digestive microflora play a vital role in the enterohepatic circulation of bile acids, by modifying bile acids and influencing feedback mechanisms. For example, conventionally grown mice have a $71 \%$ reduction in the size of their bile acid pool compared to germ free mice. Furthermore, these conventionally grown mice excrete over 4 times the amount of bile acids (Sayin et al., 2013). This emphasises the comprehensive role of the gut microbiota in regulating enterohepatic circulation. It is therefore logical changes to the gut microbiota with age will have an impact on overall cholesterol metabolism. Within the digestive tract, bile acids are metabolised by the digestive microbiota and converted to secondary bile acids. Deconjugation of primary bile acids by bacterial BSH is essential for this conversion to secondary bile acids. Deconjugated bile acids are more readily excreted than conjugated bile acids, as they are less readily reabsorbed by the apical sodium dependent bile acid transporter (ASBT) (Dawson, 2011). The excreted bile acids need to be replenished from the conversion of cholesterol (Joyce et al., 2014). With age, the rise in LDL-C can in part be explained by the decline in $\mathrm{BSH}^{+}$species, such as Lactobacillus and Bifidobacterium species (Hopkins and Macfarlane, 2002). A decline in BSH results in fewer bile acids being deconjugated, and thus more are reabsorbed, and fewer are excreted. This results in a decline in the need for bile acid synthesis, and thus cholesterol utilisation is reduced (Joyce et al., 2014). One way to combat this decline in BSH is via the administration of probiotic strains (Al-Sheraji et al., 2012). However, caution is needed when suggesting this strategy as a therapeutic intervention for the treatment of hypercholesterolaemia, as increased concentrations of secondary bile acids can increase inflammation and cancer risk in the colon (Salemans et al., 1993). This is emphasized in older individuals, where intestinal transit time is elevated, and reabsorption of conjugated bile acids is decreased, thus increasing the exposure of the intestinal mucosa to bile acids (Salemans et al., 
1993). This elevated exposure time results in the promotion of colorectal cancer in the elderly (Ajouz et al., 2014).

\subsection{Impact of Genetic Variation on Cholesterol Metabolism and Healthy Ageing}

There are several key genes involved in cholesterol metabolism; mutations to these genes can impact on plasma cholesterol levels; the response to pharmaceutical intervention; and the pathogenesis of age-related disease. In this section we will discuss several of the key genetic polymorphisms responsible for the dysfunction of cholesterol metabolism, as well as those promoting exceptional longevity. Asselbergs et al. (2012) describe 122 single nucleotide polymorphisms (SNPs) which could account for $\sim 9.9 \%$ of the variance in HDL-C levels. Furthermore, 104 SNPs could explain $~ 9.5 \%$ of the variance in LDL-C, 142 SNPs could explain $10.3 \%$ of variance in total cholesterol, while 110 SNPs could explain $8.0 \%$ of the variance associated with triglyceride levels (Asselbergs et al., 2012). In addition, genetic factors can also influence the lipoprotein response to extrinsic factors, such as pharmaceutical intervention or diet. For example, in response to increases in dietary cholesterol, individuals can be categorised as either a hypo-responder, where plasma total cholesterol increases $<0.05 \mathrm{mmol} / \mathrm{L}$, or as hyper-responders, where there is an increase of $\geq 0.06 \mathrm{mmol} / \mathrm{L}$ per each additional $100 \mathrm{mg}$ dietary cholesterol, respectively (Herron et al., 2003). Likewise, Herron et al. (2003) demonstrated ingestion of $\sim 640 \mathrm{mg} /$ day resulted in a $30 \%$ increase in LDL-C and an $8 \%$ increase in HDL-C in individuals classified as hyper-responders, whereas LDL-C and HDL-C were unaffected in individuals classed as hypo-responders. Thus, it is not surprising that previously Bosner et al. (1999) demonstrated cholesterol absorption varies from 29.0 to $80.1 \%$ in healthy subjects aged between 17 and 80 years of age. Ethnicity also plays a role in this variation, with African-Americans on average absorbing larger amounts of cholesterol than Caucasians or those from Asian descent (63.4\% vs. 56.2\%). Although, dietary intake, rather than absorption efficiency, appeared to be the dominant factor in cholesterol absorption (Bosner et al., 1999). In addition, the response to pharmaceutical intervention, such as the administration of cholesterol biosynthesis inhibitors or cholesterol absorption inhibitors is highly variable (Barber et al., 2010; Simon et al., 2005). For example, the presence of at least 1 minor allele at g.-18C resulted in a $15 \%$ improved reduction in LDL-C in response to ezetimibe + statin therapy (Simon et al., 2005).

\subsection{Cholesteryl Ester Transfer Protein}

Mutations to the gene encoding for the CETP enzyme can influence CETP activity and size (Cefalu et al., 2009). This affects both the amount of esterified cholesterol transported from HDL to LDL and VLDL, as well as lipoprotein size and number (Wang et al., 2002). There are several mutations within the CETP gene that have been discovered. Of these polymorphisms, several have been associated with lower CETP levels, reduced risk of CVD, and increased longevity. Murine models transfected with CETP undergo extensive lipid profile remodelling resulting in an increased risk for CVD (Westerterp et al., 2006). Therefore, any mutation resulting in decreased CETP, is thought to reduce CVD risk and increase life-span. For example, homozygosity for the common $1405 \mathrm{~V}$ polymorphism is associated exceptional longevity (Barzilai et al., 2003). In one case, a three-fold increase in homozygosity for the I405V genotype was observed in long lived individuals ( $24.8 \%$ vs. $8.6 \%$ ). This homozygous amino acid substitution of 405 isoleucine for valine reflected a $17 \%$ reduction in CETP 
levels, elevated HDL concentrations by $3.63 \%$, and decreased LDL levels by $7.31 \%$, in comparison to individuals homozygous for the isoleucine codon. Furthermore, LDL and HDL particles were significantly larger (Barzilai et al., 2003). These larger lipoproteins have been associated with a decreased incidence of CVD, hypertension, metabolic syndrome and neurodegeneration (Barzilai et al., 2006; Barzilai et al., 2003). It is likely that larger LDL molecules are less readily able to penetrate the arterial tissue, and therefore result in a decreased risk for atherosclerosis pathogenesis (Barzilai et al., 2003). Homozygosity for the $1405 \mathrm{~V}$ polymorphism is therefore regarded as a protective phenotype for healthy ageing (Atzmon et al., 2005; Barzilai et al., 2006).

The D442G mutation has also been described as an atheroprotective genotype, as the D442G mutation has been shown to increase LDL-C particle size, and HDL-C levels (Wang et al., 2002), in addition to decreasing the risk for CVD mortality (Koropatnick et al., 2008). However, Zhong et al. (1996) demonstrated an increase in HDL-C associated with this genotype, was correlated with an increase in CHD risk (Zhong et al., 1996). Alternatively, Hirano et al. (1997) demonstrated that a $G$ to A mutation in intron 14, which induced a rise in HDL-C exhibited a U-shaped curve of the incidence risk of ischemic change (Hirano et al., 1997). Moreover, Agerholm-Laren et al. (2000) demonstrated the A373P/R451Q genotype resulted in a decrease in HDL-C in both males and females from the Danish general population. Homozygosity for the mutation resulted in the effect being more pronounced than in heterozygotes, with $\mathrm{HDL}-\mathrm{C}$ levels of 1.19 and $1.38 \mathrm{mmol} / \mathrm{L}$ in males and females respectively compared to 1.26 and $1.62 \mathrm{mmol} / \mathrm{L}$. Non-carrier males and females had HDL levels of 1.4 and $1.74 \mathrm{mmol} / \mathrm{L}$, respectively. Although this CETP genotype induced reduced HDL-C levels, they were not associated with ischemic heart disease (IHD). Furthermore, when the authors adjusted for a group of risk factors in addition to HDL-C, the mutation resulted in a $36 \%$ reduction in risk of IHD (Agerholm-Larsen et al., 2000).

\subsection{Niemann-Pick C1-Like 1}

Intestinal absorption of cholesterol varies significantly from person to person. In healthy individuals, cholesterol absorption can range from 29.0-80.1\% (Bosner et al., 1999). This is due, in part to the genetic variation in the genes encoding for the NPC1L1 receptor, which is responsible for the clathrin-mediated endocytosis of cholesterol from the digestive tract. Cohen et al. (2006) discovered 20 polymorphisms within individuals classified as hypo-absorbers, compared to only 5 for the hyperabsorber category. Of the 20 mutations conferring a low cholesterol absorption efficiency, 18 were observed in African-Americans. This reflected the findings that these hypo-absorber phenotypes were more prevalent in African Americans (6.2\%) than white (1.8\%) or Hispanic (1.7\%) populations. These hypo-absorber phenotypes conferred an average $8.6 \%$ reduction in LDL-C (Cohen et al., 2006).

In individuals with autosomal dominant hypercholesterolaemia, lacking LDLr or apo B mutations, NPC1L1 mutations may play a role in the hypercholesterolaemic phenotype displayed. For example, it has been shown that the -133A>G polymorphism, significantly increases NPC1L1 promoter activity (Martín et al., 2010). More recently, NPC1L1 SNPs have been linked with CVD. For instance, Polisecki et al. (2010) demonstrated that homozygous carriers for the minor alleles at -18A>C, L272L, V1296V 
or U3_28650A $>$ G exhibited a $2-8 \%$ increase in LDL-C, while the risk of developing a fatal or nonfatal CHD event escalated by 50-67\% (Polisecki et al., 2010). Muendlein et al. (2015) determined that 24 variants, particularly rs55837134 were associated with future cardiovascular events. Homozygosity for the rare rs55837134 variant was associated with a 3-fold increase in cardiovascular event incidence, compared with carriers homozygous for the common allele (Muendlein et al., 2015). In contrast, Stitziel et al. (2014) demonstrated that the presence of 1 of 15 NPC1L1 inactivating mutations, as observed in $1 / 650$ individuals, corresponded to a $12 \mathrm{mg} / \mathrm{dL}$ decline in LDL-C, and a $53 \%$ reduction in cardiovascular event risk (Stitziel et al., 2014). In addition to affecting baseline lipoprotein characteristics, mutations to the NPC1L1 gene also influence the lipoprotein profile response to therapeutic intervention. For example, Simon et al. (2005) demonstrated that individuals homozygous for the common allele g. $-18 \mathrm{C}>\mathrm{A}$ exhibited a $24.2 \%$ decline in LDL-C from baseline levels with ezetimibe treatment, compared with $27.8 \%$ for individuals heterozygous for the minor allele. Thus, heterozygosity for the minor allele represented a $15 \%$ increased response to ezetimibe treatment (Simon et al., 2005). In addition to NPC1L1 mutations leading to an altered response to the NPC1L1 inhibitor ezetimibe, statin treatment efficiency is also affected. Polisecki et al. (2010) demonstrated the $-133 A>G$ SNP influenced the LDL-C response to Pravastatin treatment. Males homozygous for the minor $-133 A>G$ allele had the greatest decline in LDL-C with pravastatin treatment, while females with the major $-133 A>G$ allele exhibited the greatest response to treatment (Polisecki et al., 2010).

\subsection{Apolipoprotein E}

Apo $\mathrm{E}$ is present on chylomicrons, VLDL, IDL, and HDL and acts as a ligand for hepatic LDLr and LRP to enable lipoprotein uptake. There are three major alleles associated with the $A P O E$ gene. These are, $\varepsilon 2$, $\varepsilon 3$, and $\varepsilon 4$, which have a population frequency of $6.9,76.2$ and $16.9 \%$, respectively in a Belgian cohort (Engelborghs et al., 2003). The $\varepsilon 3$ allele is most commonly observed, and is considered as the 'neutral' apo E genotype. Along with $\varepsilon 2$, $\varepsilon 3$ preferentially binds to HDL-C, while the $\varepsilon 4$ allele has a preference for VLDL-C (Dong and Weisgraber, 1996). The presence of the $\varepsilon 4$ allele confers a 15 and $25 \%$ decline in plasma apo $E$ in males and females, respectively, compared to those with the $\varepsilon 3$ allele. This decline in apo $\mathrm{E}$ is associated with a 2 and $5 \%$ increase in LDL-C in males and females, respectively. In comparison, those with the $\varepsilon 2$ allele exhibit a 27 and $32 \%$ increase in apo $E$, which is associated with a $10 \%$ decrease in LDL-C levels (Larson et al., 2000). The presence of an $\varepsilon 4$ allele is considered a risk factor for the development of many conditions including atherosclerosis (Zende et al., 2013), Alzheimer's Disease (Rhinn et al., 2013), and multiple sclerosis (Horakova et al., 2010), in addition to accelerating telomere shortening (Wikgren et al., 2012). On the other hand, this allele has been associated with a higher vitamin D status (Huebbe et al., 2011), and has been identified as a possible protective genotype against macular degeneration (Kovacs et al., 2007). The $\varepsilon 2$ allele in contrast has been associated with an increased risk for the disease, or for its earlier onset (Tikellis et al., 2007). Furthermore, homozygosity for the $\varepsilon 2$ allele is found in $90 \%$ of individuals with hyperlipoproteinaemia type III (Mahley and Rall, 2000). The $\varepsilon 2$ isotope results in defective lipoprotein binding to LDLr, which in turn leads to incomplete catabolism of chylomicrons and VLDLC, resulting in an accumulation of cholesterol rich lipoprotein remnants (Phillips, 2014). However, only $5 \%$ of $\varepsilon 2$ homozygotes have this disease, and therefore there are other factors involved in the development of the disease (de Beer et al., 2002). With the exception of hyperlipoproteinaemia type 
III, this $\varepsilon 2$ allele has been associated with a protective phenotype against CHD (Bennet et al., 2007). Furthermore, the $\varepsilon 2$ allele is positively associated with exceptional longevity in Italian, Danish, US, and Japanese cohorts. In contrast, the presence of the $\varepsilon 4$ allele reduced the chance of reaching exceptional longevity in Spanish, Italian, Danish, US and Japanese cohorts (Garatachea et al., 2014; Schupf et al., 2013).

\subsection{Lipoprotein and Hepatic Lipase}

Another enzyme that is effected by genetic mutation is LPL. LPL is primarily found on the endothelial wall of capillaries and is responsible for the hydrolysis of triacylglycerol in chylomicrons and VLDL into FFA and MAG (Goldberg et al., 2009). A common polymorphism in the LPL gene is S447X. In a cohort of middle-aged and elderly American subjects, 44.0 and $50.6 \%$ of males and females, respectively exhibited homozygosity for the common allele, while only 12.6 and $7.6 \%$ were homozygous for the rare allele (Larson et al., 1999). Heterozygosity was displayed in 43.4 and $41.8 \%$ of males and females respectively. Females, but not males, exhibiting homozygosity for the rare allele had lower total cholesterol and LDL-C levels, when compared to heterozygotes and homozygotes for the common allele (Larson et al., 1999). This alteration to cholesterol metabolism could play a role in the association of this genotype with age-related conditions such as hypertension, type 2 diabetes mellitus and coronary artery disease (Daoud et al., 2013; MuñozBarrios et al., 2012). Hepatic lipase is responsible for the conversion of IDL to LDL, and can also be effected by genetic mutation. In contrast, the -C480T polymorphism in the hepatic lipase gene have been shown to elevate HDL-C levels. Homozygosity for the common allele was observed in $53.2 \%$ of control individuals, while $40.3 \%$ of these individuals were observed to be heterozygous. Homozygosity for the -C480T polymorphism was observed in $6.5 \%$ of healthy individuals, whereas, this was reduced to $4.7 \%$ for individuals with a paternal history of myocardial infarction before the age of 55 years, although this was not statistically significant (Murtomäki et al., 1997). Furthermore, McCaskie et al. (2006) found that although HDL-C levels were raised in an Australian population with this polymorphism, it was not associated with a decrease in CHD risk (McCaskie et al., 2006). In contrast, Fan et al. (2006) found that this polymorphism was associated with a lower coronary flow reserve, which is an early indicator of atherosclerosis (Fan et al., 2006).

\subsection{HMG CoA Reductase}

HMG CoA reductase is the enzyme responsible for the rate limiting step in cholesterol biosynthesis, and is therefore the main target for pharmaceutical intervention by statins (Istvan and Deisenhofer, 2001). Chasman et al. (2004) demonstrated that two genetic polymorphisms were not only able to influence the baseline characteristics of the lipoprotein profile, but also influence the efficacy of statin treatment. The presence of one copy of SNP 12 ( $r$ 17244841) induced an 18.9\% reduction in LDL-C and $4.6 \%$ increase in HDL-C, compared with individuals homozygous for the major allele. Whereas, heterozygotes for SNP 29 (rs17238540), exhibited 18.9 and $2.4 \%$ reduction in LDL-C and HDL-C, respectively. The presence of one of the SNPs also resulted in the diminished efficacy for cholesterol lowering treatment by pravastatin. For individuals with either SNP, the total cholesterol and LDL-C lowering efficacy was reduced 22 and 19\% respectively (Chasman et al., 2004). Thus, genetic polymorphisms in certain enzymes and receptor genes associated with cholesterol 
biosynthesis can provoke the dysregulation of cholesterol metabolism, lipoprotein profile, alter CVD risk, and the response of cholesterol metabolism to pharmaceutical intervention.

\subsection{Oxidative Stress and Cholesterol Metabolism}

The free radical theory of ageing is underpinned by the belief, that the gradual accumulation of oxidative stress with time is responsible for the ageing process (Harman, 1956, 2009). Reactive oxygen species (ROS) play a key role in the development of oxidative stress (Kandola et al., 2015). ROS are produced during mitochondrial oxidative phosphorylation, and by cells exposed to xenobiotics (Berthiaume and Wallace, 2007), pathogen associated patterns (PAMPs) (Tassi et al., 2009) or pro-inflammatory cytokines (Yang et al., 2007). Despite the processed role ROS may play in the ageing process, ROS also have useful roles in processes such as phagocyte derived bactericidal and tumouricidal activity (Li et al., 2013; Vatansever et al., 2013), nitric oxide (NO) production (Shen et al., 2014), and in insulin signalling (Bashan et al., 2009). Atherosclerosis is suggested to be a condition mediated by ROS, LDL-C and intrinsic ageing (Vogiatzi et al., 2009). Briefly, LDL-C migrate across damaged artery endothelium into the tunica intima, where an accumulation of LDL-C, immune cells, and proliferative smooth muscle cells occlude the artery lumen restricting blood flow (Hansson and Hermansson, 2011). This endothelial damage and dysfunction can be influenced by a variety of factors including smoking (Ambrose and Barua, 2004), hypertension (Li and Chen, 2005), hyperglycaemia (Popov, 2010), hyperlipidaemia (Kerenyi et al., 2006), ageing (Wang and Bennett, 2012), infection (Rosenfeld and Campbell, 2011), and hyperhomocysteinaemia (Guthikonda and Haynes, 2006). This damage results in increased ROS production, and a more permeable membrane in which LDL-C and immune cells can more freely migrate. Oxidation of LDL by ROS forms the cytotoxic and immunogenic oxLDL (Mahmoudi et al., 2011). Release of monocyte chemotactic protein-1 (MCP-1) by endothelial smooth muscle cells and macrophage that have already localised in the tunica intima, leads to the migration of monocytes across the endothelium where they differentiate into macrophage (Dewald et al., 2005). These macrophage then engulf oxLDL via scavenger receptors SR-A and CD36, forming lipid-laden foam cells (Korporaal et al., 2007). Meanwhile, T cells, mainly Th1, migrate across the endothelium and release pro-inflammatory cytokines such as IL-2, IL-12 and IFN- $\gamma$ to intensify the immune response (Baidya and Zeng, 2005). Foam cells, macrophage, and T-cells then combine to form a fatty streak. The macrophage also secrete the pro-inflammatory cytokines TNF $\alpha, \mathrm{IL}-1 \beta, \mathrm{IL}-6$, and IL-12, in addition to the mitogen platelet derived growth factor (PDGF), which induces the proliferation of smooth muscle cells of the tunica media forming a cap for the plaque (Ross et al., 1990). This segregates the plaque from the blood, however the plaque cause the artery to harden and narrow, restricting blood flow. Subsequent instability in the plaque can result in it rupturing; which can block the supply of blood to the heart causing a myocardial infarction, or to the brain, triggering an ischaemic stroke (Bentzon et al., 2014). In addition to the effects of ROS on LDL, it has also been shown to interact with the atheroprotective particle HDL, it has been suggested HDL is oxidised during the pathogenesis of atherosclerosis, causing HDL to lose its protective properties and transform into a proinflammatory and proatherogenic mediator. These oxidised HDL, oxHDL, have been shown to promote smooth muscle cell proliferation and migration in a dose dependent manner, thus aiding in the progression of atherosclerosis pathogenesis (Wang et al., 2014). Further to this, oxHDL, have also been shown to induce ROS production, upregulate the expression of the proinflammatory cytokine TNF- $\alpha$, and 
upregulate the expression of prothrombotic cyclooxygenase-2 (COX-2) and plasminogen activator inhibitor-1 (PAI-1) (Callegari et al., 2006; Norata et al., 2004; Soumyarani and Jayakumari, 2012).

\subsection{Caloric Restriction}

466

467

468

469

470

471

472

473

474

475

476

477

478

479

480

481

482

483

484

485

486

487

488

489

490

491

492

493

494

495

496

497

498

499

500

501

502

503

504

CR, a dietary regime defined by a $20-40 \%$ reduction of calories, which does not induce malnutrition (Taormina and Mirisola, 2014), has been demonstrated to extend life-span in a diverse range of organisms, however its effect on humans has not be fully established (Barzilai et al., 2012; Guarente, 2013). CR has been associated with many metabolic effects linked to ageing and longevity. For example, CR has been associated with a reduction in the release of ROS from complex I of mitochondria within the cardiac tissue of rodents (Gredilla et al., 2001). Therefore, there is a prevailing hypothesis within gerontology, that the positive effects of this dietary regime are mediated through a reduction in ROS. However, it is possible that the beneficial effects of CR on health-span extend beyond this particular aspect of ageing, as evidence suggests, that metabolic rate is unaffected by CR in murine models (Hempenstall et al., 2010).Moreover, it is considered that ageing is associated with the accumulation of ROS and oxidative damage. Conversely, recent evidence has suggested that low grade oxidative damage may be beneficial. As an example, glucose restriction has been associated with an increase in oxidative stress in Caenorhabditis elegans, which is thought to increase resistance to further oxidative stress, and thus extend life-span via mitochondrial hormesis (Schulz et al., 2007). Alternatively, murine models have demonstrated that calorie restriction can prevent the age-related decline of heat shock proteins (HSPs), which are induced following exposure to stress to protect cells and organs from the stressor (Colotti et al., 2005). CR has also been shown to have a positive effect on cholesterol metabolism in mammals. For instance, Edwards et al. (1988) investigated the effect of CR on LDL-C over a five year period in Rhesus monkeys and found this regime reduced LDL-C levels when compared to a control group (Edwards et al., 1998). Much more recently, it has also been suggested CR improves metabolic health generally (Ristow and Zarse, 2010). For instance, Colman et al. (2014) demonstrated a 2.9 times increased risk for all age-related causes of death, in Rhesus monkeys undertaking a control diet, when compared to those undertaking a 30\% CR diet. CR also increased the survival rate of those animals by 3.63 times (Colman et al., 2014). The Comprehensive Assessment of Long-Term Effects of Reducing Calorie Intake (CALERIE) study provides information on the effect of CR in humans. Phase one of this program examined healthy, but overweight individuals (BMI 25$29.9 \mathrm{~kg} / \mathrm{m}^{2}$ ) from three centres across America who underwent $20-25 \%$ CR. From these studies it was determined two biomarkers of longevity, fasting insulin and body temperature were reduced following 6 months of $25 \%$ CR. The authors of this study postulated that CR increases longevity via a reduction in metabolic rate (Heilbronn et al., 2006). In terms of a direct impact on lipid metabolism, CR was shown to decrease weight, fat mass and visceral adipose tissue in participants. These changes were associated with an increase in insulin sensitivity (Larson-Meyer et al., 2006). The project has recently progressed to phase 2 trials, to examine the effects of $C R$ on healthy nonobese (BMI 22-28kg/ $\mathrm{m}^{2}$ ) individuals (Stewart et al., 2013).

The effects of CR in humans has also been investigated by Fontana et al. (2004). In this study, the lipoprotein profile and carotid artery intima-media thickness of 18 members of the Caloric Restriction Society, whose members practice long term self-imposed CR (3-15 years), was compared with 18 control individuals. This investigation revealed a number of interesting findings about the 
interaction of CR with lipid metabolism, including a decline in total cholesterol, LDL-C, and triacylglycerol by 19.1, 29.5 and $63.8 \%$, respectively following CR. HDL-C was also affected by CR, with a $51.2 \%$ elevation in levels. This was in addition to a reduction in other risk factors associated with CVD including, blood pressure and the inflammatory marker C-reactive protein (CRP).Together with the carotid intima-media thickness reduction of approximately 40\%, CR appears to have an atheroprotective effect (Fontana et al., 2004). We can conclude from these studies, although it is clear that CR increases life-span in many species, the underlying mechanisms are still ambiguous. However, in mammals a favourable lipid profile could be one component of a much broader cardioprotective protective effect brought on by CR which ultimately contributes to life span extension.

\subsection{Sirtuins, mTOR and Cholesterol Biosynthesis}

Mechanistic target of rapamycin (mTOR) is an evolutionarily conserved serine/threonine protein kinase of the phosphatidylinositol-3-OH kinase (PI(3)K)-related family that regulates an array of anabolic and catabolic pathways at the mRNA expression level (Johnson et al., 2013). mTOR acts as a key metabolic sensor in a wide range of biological activities, both at a cellular and organism level. This ability to act as a regulator causes it to respond to a plethora of both intrinsic and extrinsic cellular signals (Mc Auley et al., 2015). These metabolic cues include changes to oxygen, nutrient and hormonal levels. mTOR forms the catalytic subunit of two discrete signalling complexes, known as mTOR complexes 1 and 2 (mTORC1 and mTORC2). The mTOR pathway impacts cell growth and proliferation by provoking anabolic processes, including biosynthesis of proteins, lipids and organelles, and by restricting catabolic processes, such as autophagy. There is a large body of evidence which has been generated from several animal models that link the activities of mTORC1 to the beneficial effects of CR, and thus longevity. Discussing these studies is beyond the scope of this review, rather we will focus on how mTOR impacts cholesterol biosynthesis. Central to the regulation of cholesterol biosynthetic gene expression is the SREBP family of transcription factors (Horton et al., 2002). It has been observed that silencing of SREBP inhibits Akt (Protein kinase B (PKB)) dependent lipogenesis. Akt is an upstream regulator of mTOR, and it has been suggested PI3K/Akt/TOR pathway regulates protein and lipid biosynthesis in an orchestrated manner (Porstmann et al., 2008). More recently, Peterson et al. (2011) demonstrated TORC1 regulates SREBP by controlling the nuclear entry of lipin 1 , a phosphatidic acid phosphatase. It was found that inhibition of hepatic mTORC1 impaired SREBP function and resulted in mice becoming tolerant in a lipin 1-dependent fashion, to hepatic steatosis and hypercholesterolemia induced by a high-fat and cholesterol diet (Peterson et al., 2011). Moreover, a recent study that examined non-alcoholic fatty liver disease under conditions of inflammation in apolipoprotein E knockout mice, demonstrated the inhibition of mTORC1 activity blocked the translocation of SCAP/SREBP-2 complex from the endoplasmic reticulum to the Golgi, and decreased the expression of LDLr and SREBP-2. These effects were accompanied by an increase in LDLr degradation (Liu et al., 2015). Thus, this study suggests that there could be an important link between mTOR and LDLr turnover, which has significant implications for whole body cholesterol balance and healthy ageing.

Sirtuins have also been shown to impact cholesterol biosynthesis. There are 7 known mammalian sirtuins, that function as $\mathrm{NAD}^{+}$-dependent deacetylases, which are involved in a wide range of cellular activities including nutrient sensing and DNA repair (Chang et al., 2009; de Magalhães et al., 2012). The most well studied of the sirtuins, SIRT1, plays a role in various metabolic processes that enable the cell to adapt to changes in nutrient levels. For instance, SIRT1 plays a part in modulating 
hepatic gluconeogenesis, insulin secretion, fat mobilisation, and stress responses (Satoh et al., 2011; Wei et al., 2011). SIRT1 also deacetylates the nuclear receptor liver $X$ receptor $\alpha$ (LXR $\alpha)$ to induce synthesis of the transporter ABCA1, a mediator of HDL and RCT. SIRT1 KO mice display reduced plasma HDL-C levels in addition to an accumulation of cholesterol in the liver (Li et al., 2007). SIRT1 has also been suggested to be cardioprotective. For instance, evidence indicates it has a role in preventing cardiac hypertrophy (Planavila et al., 2011). In contrast, it has been demonstrated that inhibition of SIRT2 can reduce sterol biosynthesis by decreased trafficking of SREBP-2, as a mechanism of neuroprotection in cellular and invertebrate models of Huntingtons Disease (LuthiCarter et al., 2010). Moreover, Tao et al. (2013) have suggested that Sirt6 is a critical factor for Srebp2 gene regulation. Hepatic deficiency of Sirt6 in mice resulted in elevated serum and hepatic cholesterol levels. Sirt6 is recruited by forkhead box O (FoxO)3 to Srebp2, where Sirt6 deacetylates histone $\mathrm{H} 3$ at lysines 9 and 56, thus promoting a repressive chromatin state. It was found that Sirt6 or FoxO3 overexpression improved hypercholesterolemia in diet-induced or genetically obese mice (Tao et al., 2013). Therefore, Sirt6 and FoxO3 could have a crucial role to play in the regulation of cholesterol homeostasis

\subsection{Can Diet Mitigate the Effect Ageing has on Cholesterol Metabolism?}

During the 1950s, the Seven Countries Study (SCS) began exploring the role of diet and lifestyle on disease rates in populations from various countries. Amongst the findings reported from these studies were the causal association between, serum cholesterol, blood pressure and smoking and CHD mortality rates (Menotti et al., 1998; Menotti et al., 2004a; Menotti et al., 2004b), whereas, diets high in saturated fat, and trans fats were associated with higher serum cholesterol and thus CHD risk (Kromhout et al., 1995). Conversely, diets high in vegetables, rich in fibre and antioxidants, promoted significant reductions in CHD risk (Buijsse et al., 2008; Streppel et al., 2008). Dietary regime is therefore an important factor that should be analysed and adjusted in order to reduce CHD risk and promote longevity. The important role of dietary and other lifestyle interventions on lifespan can be emphasised by analysing the North Karelia Project. Internationally, Finnish males, especially those in the province of North Karelia, had the highest rate of CHD in the late 1960s, as a result of a diet high in salt and saturated fat, and low in vegetables, in addition to high rates of smoking and physical inactivity (Puska, 2008). In order to combat this burden, a low-resource, community-based intervention study titled the North Karelia Project was implemented in 1972 (Puska, 1973). The North Karelia Project aimed to reduce CHD morbidity and mortality rates by reducing LDL-C concentrations and blood pressure by improving diet and exercise patterns; and reducing smoking rates. The project resulted in the most rapid decline in CHD mortality in the world. Within 5 years, a 4.1 and $1.2 \%$ reduction in serum cholesterol was exhibited in men and women, respectively (Puska et al., 1979). These figures increased further to a $21 \%$ and $23 \%$ decline in total cholesterol under re-examination in 2007 (Vartiainen et al., 2010). The initial five year study resulted in a 17.4 and $11.5 \%$ reduction in CHD risk in males and females, respectively. Following a further 25 years of implementation, this decline was amplified to a $60 \%$ reduction (Puska et al., 1979; Vartiainen et al., 2010). This 30 year project reflected an $85 \%$ decrease in CHD-related mortality (Puska, 2008). The impact of lifestyle on cholesterol metabolism, and consequently CVD risk is therefore significant. The role diet and lifestyle plays in reducing risk of age related diseases and in extending life-span is also apparent in those who consume a Mediterranean diet. This dietary 
pattern has been studied extensively, particularly, the role it plays in optimising lipoprotein profile and reducing CVD risk

\subsection{Mediterranean Diet}

The Mediterranean diet is characterised by a high intake of vegetables, fruits, legumes, nuts, cereals and olive oil, and a low intake of dairy, and red and processed meats (Trichopoulou and Lagiou, 1997). Richard et al. (2012) demonstrated a five week Mediterranean diet decreased LDL-C by $9.9 \%$, even in the absence of weight loss in men with metabolic syndrome. It was suggested this dietary pattern was able to effect LDL-C levels, by increasing LDL-C clearance as well as reducing cholesterol absorption. This was thought to be due to an increase of dietary phytosterols, nutrients, monounsaturated fatty acids (MUFA), polyunsaturated fatty acids (PUFA), fish oils and fibre (Richard et al., 2012; Woodside et al., 2015). The Mediterranean diet affects cholesterol metabolism as follows. Firstly, it is postulated PUFA increases LDLr expression (Fernandez and West, 2005). Furthermore, studies have indicated plant sterols can reduce cholesterol absorption by $30-50 \%$ (Law, 2000), although the expression of ABCG5/G8 and NPC1L1 are thought to be unaffected by sterol ingestion (Field et al., 2004). Consumption of a Mediterranean diet has not only been associated with a reduction in the incident rate of the age related diseases, type II diabetes mellitus, CVD, and cancer, by 52, 30, and 12\%, respectively (Benetou et al., 2008; Estruch et al., 2013; Salas-Salvadó et al., 2011). Furthermore, individuals, from Spain or Italy for example, born in 2000, are expected to live on average 2 years longer than individuals from the UK or USA. In addition, the healthy life expectancy of these individuals is also 2 years more (WHO, 2015). Thus, the Mediterranean diet is believed to play a role in prolonging both health-span and life-span. The Mediterranean diet has also been utilised as a strategy to treat age-related disease onset. For example, de Lorgeril et al. (1999) reported a $9.11 \%$ reduction in the rate of secondary cardiovascular events in patients who adhered to a Mediterranean diet compared to those that followed a standard diet. It was determined that each $1 \mathrm{mmol} / \mathrm{L}$ increase in total cholesterol resulted in a $20-30 \%$ increase in the risk of recurrence (de Lorgeril et al., 1999). Therefore, a Mediterranean diet that results in decreased cholesterol levels is not only protective against primary cardiovascular events but also secondary events. The substantial evidence demonstrating the potential benefit of a Mediterranean diet on prolonging health-span as well as life-span has resulted in large-scale studies, such as the NU-AGE project arising (Santoro et al., 2014). The NU-AGE project aims to utilise the Mediterranean diet as a treatment strategy to slow the rate of inflammaging, in addition to establishing the molecular mechanisms underpinning the anti-inflammaging effect of this dietary approach (Santoro et al., 2014).

\subsection{The Recent Emergence of the Gut Microbiome}

The gut microbiome has a range of metabolic roles which maintain host heath, including; facilitating the digestion of starch, fibre, and sugars (Szilagyi et al., 2010); producing short-chain fatty acids (den Besten et al., 2013; Yu et al., 2010); vitamin absorption (Beulens et al., 2013); enhancing host immunity; preventing allergies (Shen and Clemente, 2015) and facilitating enterohepatic circulation of bile acids (section 3.2). Alteration to the microbiome can impact host health and this has increasingly been investigated as a contributor to disease. The close relationship between the microbiome and its human host has resulted in humans being described as metaorganisms (Biagi et 
al., 2012). The impact of the microbiome on overall health was recently illustrated by a female subject that underwent a faecal transplant from her overweight, but otherwise healthy daughter for the treatment of recurrent Clostridium difficile infection. Post-transplant, the recipient experienced substantial weight gain, resulting in a weight gain of 41 pounds and an increase in BMI from 26 to 34.5 at 36 months observation (Alang and Kelly, 2015). This suggests 'obesity promoting' microbiota can be transmitted from human to human, as previously observed in rodents (Ridaura et al., 2013). Understanding the role of the microbiome in health is challenging, due to complex bidirectional interactions with many biological systems. For example, it has been implicated in enhancing alveolar macrophage function in lung infections (Schuijt et al., 2015) and is thought to influence brain morphology and function (Fernandez-Real et al., 2015). A decrease in Actinobacteria with age is associated with amygdala disruption and thalmic microstructure, reduced motor speed and attention, in addition to increased intra-abdominal fat (Fernandez-Real et al., 2015). Conversely, in a classic study, Killian et al. (1998) showed mice exposed to stress exhibited altered intestinal function (Kiliaan et al., 1998). Moreover, administration of probiotic strains impact behaviour by improving mood and decreasing anxiety symptoms in both rodent and humans (Messaoudi et al., 2011; Savignac et al., 2015; Steenbergen et al., 2015). Thus, a bidirectional relationship exists between the gut and brain and it is likely that a similar relationship exists for other organ systems.

\subsection{The Gut Microbiome and CVD}

There is an association between the microbiota and CVD risk. This could be mediated via its effects on bile acid metabolism, or by its contribution to choline diet-induced trimethylamine $\mathrm{N}$-oxide (TMAO) production (Joyce et al., 2014; Koeth et al., 2013). Susceptibility to atherosclerosis has also been demonstrated to be transferable by microbiota transplantation in murine models (Gregory et al., 2015). Moreover, gut microbiota dysbiosis has been associated with increased low-grade inflammation, which is linked with the development of atherosclerosis (Chistiakov et al., 2015). To examine the role of the gut microbiome on CVD risk, Fu et al. (2015) explored the potential relationships between operational taxonomic units (OTUs) with BMI, and blood lipids. High bacterial diversity was associated with a decreased $\mathrm{BMI}$, and triglyceride levels, whilst a positive correlation was observed with HDL-C levels. A total of 66 OTUs were associated with BMI, while 114 were associated with triglycerides, and 34 OTUs with HDL. In particular Clostridiaceae/Lachnospiracease was able to modulate LDL-C levels. Fu et al. (2015) estimated that the gut microbiota is independently responsible for $\leq 6 \%$ of blood lipid level variation (Fu et al., 2015).

\subsection{The Gut Microbiome and Ageing}

Due to inter-individual variation, there is conflicting evidence on microbiome changes during ageing. In an elderly Irish cohort (65-96 years), the proportion of Bacteriodetes ranged from 3-92\%, while Firmicutes ranged from 7-94\% (Claesson et al., 2011). Further differences in the gut microbiome have also been observed in other population groups. For example, Clostridium cluster XIVa has been observed to decrease with age in Japanese, Finnish, and Austrian cohorts (Hayashi et al., 2003; Hippe et al., 2011; Makivuokko et al., 2010), whereas an increase has been observed in German and Italian cohorts (Mueller et al., 2006). Biagi et al. (2010) reported higher levels of the Clostridium cluster XIVa in elderly Italians (49\%), when compared to younger individuals (44\%), although the levels did reduce slightly in centenarians (34\%) (Biagi et al., 2010). These conflicting results make it difficult to 
establish an overall picture of how ageing effects the microbiome. However, it is likely that diet, lifestyle, antibiotic usage, and host health status accounts for much of this variation (Candela et al., 2014; Claesson et al., 2012; O'Sullivan et al., 2013). For example, the reduction in species diversity witnessed with age in humans (Biagi et al., 2010), is amplified in those housed in long-term residential care (Claesson et al., 2012). Furthermore, a carnivorous or herbivorous diet can induce changes to the microbiome composition to favour metabolism of protein or carbohydrates (David et al., 2014). Moreover, Evard et al. (2012) demonstrated that a high fat diet decreased the expression of regenerating islet-derived 3 gamma (Reg3g), an antimicrobial lectin with activity against Grampositive species. This reduction of Reg3g increases colonisation of the intestinal epithelium, causing alterations in the microbiome, including a decrease in the Firmicutes/Bacteroides ratio. However, prebiotic administration is able to counteract this decrease in Reg3g (Everard et al., 2014).

Bacteria from the plyla Bacteroidetes and Fimicutes contribute to $95 \%$ of faecal microbiota across ages, however a slight decline has been observed in centenarians (93\%) (Biagi et al., 2010), while the Firmicutes/Bacteroidetes ratio also lowers with age (Park et al., 2015). In addition, Claesson et al. (2011) demonstrated Firmicutes increased from $40 \%$ to $51 \%$, and Bacteriodetes decreased from $57 \%$ to $41 \%$, when comparing a young cohort (28-46 years old) to an elderly cohort ( $\geq 65$ years old) (Claesson et al., 2011). In contrast, Biagi et al. (2010) found that the Firmicutes/Bacteroidetes ratio increased from 3.9 in young individuals to 5.1 in elderly individuals, before decreasing to 3.6 in centenarians (Biagi et al., 2010). Furthermore, species diversity and number of Bifidobacterium and Lactobacillus species commonly declines with age (Hopkins and Macfarlane, 2002; Wang et al., 2015). Hopkins and Macfarlane (2002) found that species diversity of Bifidobacterium and Lactobacillus decreased by 57.1 and $45.5 \%$ respectively between healthy young adults aged 21-34, and healthy elderly individuals, aged 67-73 years old. The number of Bifidobacterium and Lactobacillus species, measured as $\log _{10}$ CFU/g wet weight of faeces, decreased by 53.2 and $52.2 \%$ respectively with age (Hopkins and Macfarlane, 2002). In addition, with age, there is an increase of potentially pathogenic facultative anaerobes. For example, Proteobacteria increased from $1.2 \%$ to $2.6 \%$ in human centenarians, whilst bacilli increased from $5 \%$ to $12 \%$ (Biagi et al., 2010).

Evidence suggests centenarians have further altered gut microbiota than elderly cohorts (Biagi et al., 2010). For example, when comparing the gut microbiota of cohorts exhibiting 'normal life-spans' (urbanised town communities, UTC) with those exhibiting exceptional longevity (longevity village communities, LVC) in South Korea, LVC individuals displayed significantly higher numbers of Bacteroides, Prevotella, and Lachnospira, while levels of Dialister, Subdoligranulum, Megamonas, EF401882_g, and AM275436_g were greater in UTC individuals. The content of pro-inflammatory LPS was also significantly lower in the faecal samples of the LVC cohort. Higher LPS levels were associated with increased meat intake, decreased vegetable intake, and the presence of several bacterial species found only in the UTC cohort (Park et al., 2015). These factors could influence the progression of low-grade inflammation. This view is consolidated as bacteria associated with antiinflammatory effects were significantly higher in the LVC cohort, making it possible that factors such as diet, influence microbiome composition, and result in a drop in pro-inflammatory LPS and a concomitant reduction in inflammaging. Additionally, Biagi et al. (2010) found that an age-related increase in potentially pathogenic Proteobacteria was correlated with the upregulation of proinflammatory IL-6 or IL-8 (Biagi et al., 2010). This further consolidates the belief, that reducing proinflammatory mediators such as LPS/cytokines could reduce inflammaging and promote healthy ageing (Biagi et al., 2010; Park et al., 2015). 
The microbiome also affects metabolism. By investigating the bacterial genetic material in human faecal samples, Rampelli et al. (2013) revealed an increase in the bacterial genes involved in tryptophan metabolism with age. It is plausible that this age-dependent increase in bacterial tryptophan metabolism, decreases host bioavailability, a phenomenon which is implicated in a variety of inflammatory related conditions (Capuron et al., 2011; Murr et al., 2015). Furthermore, the abundance of genes involved in SCFA production reduced with age. Moreover there was a decrease in bacterial saccharolytic potential, while an increase in proteolytic potential, diverted metabolism towards putrefaction. Furthermore, increasing age corresponded with the enrichment of genes relating to pathobionts such as Escherichia (Rampelli et al., 2013). Future investigations will no doubt explore further bidirectional relationships between the regulation of lipid metabolism, the gut microbiome and intrinsic ageing.

\subsection{Current and Future Therapeutic Strategies}

The emerging bi-directional relationship between the gut microbiome and human host promotes this as a potential therapeutic target for the regulation of many host systems. Probiotic administration has been highlighted as an effective immunomodulator, which can have potential benefits on many diseases (Patel et al., 2015). For example, Makino et al. (2010) demonstrated that a daily probiotic intake for 8-12 weeks resulted in a 2.6 times lower risk of becoming infected with the influenza virus in individuals $\geq 40$ years old (Makino et al., 2010). Furthermore, it has been demonstrated that administration of probiotics for several weeks prior to a flu vaccination, increases initial antibody titres in addition to maintaining these enhanced levels for increased lengths of time in elderly cohorts (Boge et al., 2009; Nagafuchi et al., 2015). As well as this, probiotics have been found to influence cholesterol metabolism. Al-Sheraji et al. (2012) demonstrated an 8 week probiotic supplementation in an elderly murine model significantly reduced plasma total cholesterol, triglycerides, LDL-C, and VLDL-C, in addition to increasing HDL-C levels. Moreover, probiotic supplementation significantly reduced the atherosclerotic index of these animals (Al-Sheraji et al., 2012). These alterations in plasma cholesterol levels could be due to a number of factors, including, the generation of SCFAs which may reduce the rate of hepatic cholesterol synthesis, the increase in bile acid deconjugation resulting in reduced cholesterol absorption, and the increase in bile acid excretion (Al-Sheraji et al., 2012; Begley et al., 2006; Hara et al., 1999).

Furthermore, dietary interventions such as the Dietary Approaches to Stop Hypertension (DASH) and portfolio diets, which target the risk factors for CVD, hypertension and hypercholesterolaemia respectively, can be utilised (Jenkins et al., 2015; Keith et al., 2015; Rifai and Silver, 2015). For example, a recent meta-analysis determined the DASH diet lowered systolic pressure by $6.74 \mathrm{mmHg}$, and diastolic blood pressure by $3.54 \mathrm{mmHg}$ (Saneei et al., 2014). Although the portfolio diet is less successful in lowering blood pressure, it is effective at modifying the lipoprotein profile. Jenkins et al. (2011) observed a 13.1 and $13.8 \%$ reduction in LDL-C in individuals undertaking the routine and intensive portfolio diets over a 6 month period. Adherence to the routine or intensive portfolio diet resulted in a respective calculated 10 year CHD risk reduction of 10.8 and $11.3 \%$ respectively (Jenkins et al., 2011). As there is a significant risk reduction for CHD, and few adverse reactions associated with these diets, wide-scale utilisation in elderly individuals may play a role in maintaining good health in later years. Further to this, dependence on pharmaceutical intervention may be reduced. Moreover, many of the food items associated with these diets contain phytochemicals that can 
positively modulate infection and/or inflammaging and its related diseases (London and Beezhold, 2015; McCarthy and O'Gara, 2015; Shayganni et al., 2015). Another viable therapeutic avenue could be to inhibit PSCK9. Recently inhibition of this enzyme has proven to be effective at lowering LDL-C in patients with hypercholesterolaemia. By inhibiting PCSK9, the rate of LDLr degradation is reduced, and the rate of LDL-C clearance can be maintained. A systemic review and meta-analysis of phase 2 or 3 randomised controlled trials revealed treatment with monoclonal antibodies targeting PCSK9 lowered LDL-C levels by $47.49 \%$, and reduced all-cause mortality and myocardial infarction risk, although cardiovascular mortality was unaffected (Navarese et al., 2015).

\subsection{The role of Mathematical Modelling in Identifying Future Therapeutic Strategies}

It is clear from the biological mechanisms and complex interactions outlined in this review that studying their dynamics is challenging. In recent years, research in this area has benefitted from adopting a systems biology paradigm to study the inherent complexities associated with ageing and metabolism (Mc Auley and Mooney, 2015a; Mc Auley et al., 2013; McAuley et al., 2009). The systems biology approach provides a framework for dealing with this intrinsic complexity. Central to this approach is the use of mathematical models, which work in tandem with experimental work by integrating experimental data and enabling dynamic behaviour to be modelled in a holistic manner (Enrique Salcedo-Sora and Mc Auley, 2016; Kilner et al., 2016; Mooney et al., 2016). This contrasts with the often reductionist approach that is commonly used in experimental biology, which generally focuses on a small number of processes operating in isolation. The utility of mathematical modelling lies in its inherent ability to facilitate hypothesis exploration, and to make predictions about the behaviour of the biological systems in question, and can often lead to a deeper understanding of the biology. Recently, there has been three excellent reviews of mathematical models in this area (Mc Auley and Mooney, 2015b; Paalvast et al., 2015; Parton et al., 2015), therefore our aim here is not to review each of these models, but to provide a synopsis of how mathematical models of cholesterol metabolism, and its associated processes can be used to enhance our understanding of how ageing impacts this core biological system. We addressed this problem recently by constructing a whole body mathematical model of cholesterol metabolism and its age associated dysregulation (Mc Auley et al., 2005; Mc Auley et al., 2012). Within this framework we included several key mechanisms, including LDLr turnover, intestinal cholesterol absorption, and endogenous cholesterol synthesis. Using the model, a number of mechanisms were explored. Firstly, using an in silico simulation we gradually reduced the efficiency of cholesterol absorption. Interestingly, by increasing cholesterol absorption from $50 \%$ to $80 \%$ by 65 years, we were able to show that LDL-C increased by $34 \mathrm{mg} / \mathrm{dL}$ from its baseline value of $100 \mathrm{mg} / \mathrm{dL}$ at 20 years of age in a healthy adult male. However, the key finding of the model centred on hepatic LDLr. Using the model we were able to show that by decreasing the activity of the LDLr to $50 \%$ by age 65 years, this produced a rise in LDL-C of $116 \mathrm{mg} / \mathrm{dL}$ from a base line value of 100mg/dL at age 20 years in a healthy male. Our model is coded in the Systems Biology Markup Language, SBML (Hucka et al., 2003), and is archived in the BioModels database (Le Novere et al., 2006) (http://www.ebi.ac.uk/biomodels-main/BIOMD0000000434). This makes the model straightforward to adapt and update.

Recently other groups have adapted the model, for example, Mishra et al. (2014) included the variables body weight and physical activity and explored cholesterol absorption in depth (Mishra et 
al., 2014). Moreover, Paalvast and colleagues used the model to conduct an in silico experiment utilizing the statin, simvastatin (Paalvast et al., 2015). To simulate this effect, the authors reduced hepatic cholesterol synthesis by $75 \%$. This resulted in a reduction in LDL-C of $14 \%$ and $33 \%$ in six weeks and one year respectively. In recent years a number of other models have mathematically represented various aspects of cholesterol metabolism. Briefly, these include models of cholesterol biosynthesis (Bhattacharya et al., 2014; Kervizic and Corcos, 2008; Mazein et al., 2013; Watterson et al., 2013), lipoprotein dynamics (Chapman et al., 2010; Hübner et al., 2008; Shorten and Upreti, 2005; Sips et al., 2014), LDLr regulation (Shankaran et al., 2007), hepatic LDL-C endocytosis (Wattis et al., 2008), and RCT (Lu et al., 2014). Most of these models do not focus on the ageing process as such, but it is possible they could be adapted and merged to explore in depth some of the changes that occur within cholesterol metabolism during ageing, discussed in this review, in particular the interaction of the gut microbiome with cholesterol metabolism.

\subsection{Discussion}

Developed populations are ageing, resulting in an increase in the diseases associated with ageing. Of the diseases whose prevalence increases with age, CVD related morbidity is by far the most common. The risk factors for CVD are many, however together with classic factors such as chronological age, smoking, sex, blood pressure and diabetes; lipid biomarkers have become the cornerstone in determining CVD risk. It is generally accepted the relationship between CVD risk and the dysregulation of lipid metabolism is at least in part due to the strong association that exists between elevated total cholesterol/LDL-C and atherosclerotic plaque formation. Conversely, due to its role in RCT, HDL-C is widely regarded as being anti-atherogenic, and evidenced by the inverse correlation between HDL-C levels and CVD. Fundamentally, cholesterol metabolism is maintained by a subtle balancing act between dietary ingestion, intestinal absorption, whole-body synthesis and excretion. These processes work in a coordinated fashion over a diverse range of spatial and temporal scales to help maintain whole body cholesterol balance. Changes to any of these processes can have a direct impact on the levels of LDL-C and HDL-C, thus indirectly influencing CVD risk. Changes to any of these processes can have a direct impact on the levels of LDL-C and HDL-C, thus indirectly influencing CVD risk, a finding of paramount importance, when considering the complex interactions that exist between cholesterol metabolism and the ageing process. This review has highlighted the ageing process does not affect cholesterol metabolism at solely one, or even a number of sites, but rather each regulatory component of cholesterol metabolism is affected by the ageing process. Worryingly, there is a paucity of studies detailing the mechanistic changes that occur during metabolism of this nutrient and ageing, and of those that exist, the majority tend to focus on murine models and were completed several decades ago. Despite this, our review uncovered a number of important findings about how cholesterol metabolism affects ageing. It was revealed that NPC1L1 expression significantly increases in the duodenum and jejunum with age, while ABCG5/G8 expression is suppressed. Moreover, in humans it has been found that the rate of bile acid synthesis declines with age and occurs with a concomitant reduction in the hepatic expression of the rate limiting enzyme of bile acid synthesis, CYP7Al. Also, from an intestinal perspective it has been suggested that the rise in LDL-C that accompanies ageing is due to a decline in $\mathrm{BSH}^{+}$species, such as Lactobacillus and Bifidobacterium. However, when we examined how lipoprotein dynamics change with age, it was suggested that the mechanistic explanation for the rise in LDL-C during ageing is due 
to a reduction in the clearance rate for LDL-C from the circulation. This assertion is certainly in line with the central finding from our recent mechanistic model of whole body cholesterol metabolism, which revealed that a reduction in the hepatic clearance rate of LDL-C is the central driver in dysregulating cholesterol metabolism. However, for the purposes of abstraction our model did not incorporate many of the mechanisms outlined in this review. Therefore, it is our opinion that the dysregulation of cholesterol metabolism is the cumulative effect of ageing on all the components of cholesterol metabolism and it is naive to single out any one aspect in particular. This view is supported by additional findings from this review that revealed how other important aspects of cholesterol metabolism are effected by the ageing. For instance, oxidative stress was shown not only to be involved in the progression of atherosclerosis but to also be involved in the oxidation of HDL particles. Moreover, various molecular mechanisms involved intracellular cholesterol homeostasis and biosynthesis have been shown to be effected by the metabolic regulators mTOR and sirtuins. These cellular metabolic hubs are widely regarded as having a key role to play in intrinsic ageing and health-span. For instance, mTORC1 regulates SREBP levels which in turn results in altered LDLr expression. In addition, Sirt6 has been identified as being involved in Srebp2 gene regulation. Collectively these findings emphasize that it not the dysregulation of one or even a few biological mechanisms; rather, age related dyslipidaemia is likely to be the result of a combination of several factors and future therapeutic interventions should be underpinned by this.

This review also revealed diet has a key role to play in modulating cholesterol metabolism and could be a key therapeutic avenue to mitigate the effects ageing has on lipid metabolism. The central dietary paradigm of ageing research has been CR. This regime has been shown to have a positive cardioprotective effect in humans, part of which is brought about by an improvement in blood lipid profile in subjects undertaking this diet. More conventional diets also affect cholesterol metabolism. The high levels of dietary phytosterols, MUFA, and PUFA typically found in the Mediterranean diet for instance, have been shown to modulate cholesterol metabolism, by increasing hepatic expression of LDLr, in addition to reducing cholesterol absorption. Thus, experimental evidence suggests employment of healthy diets such as the Mediterranean diet, and supplementation with probiotics for example, could be utilised to slow the rate of LDL-C accumulation, associated with the ageing process.

One way in which we could explore the relationship between diet, ageing and cholesterol metabolism further would be to use mechanistic mathematical models. Recently, mathematical models have been used to explore the dynamics of cholesterol metabolism and the effect that both ageing and dietary changes have on it. One area that a mathematical model could be used to explore in greater depth, is the bi-directional relationship between the gut microbiome and cholesterol metabolism. Thus, modelling could help to identify alternative therapeutic targets, which could reduce the dependence on pharmaceutical intervention in older people to improve blood lipid profile.

\subsection{Conclusion}

It is evident, the breakdown of cholesterol metabolism associated with ageing results in increased LDL-C and has important implications for health-span. Dietary intervention offers a potential nonpharmacological avenue that could be invaluable for mitigating the insidious effects ageing has on 
this system. In recent years, there have been an increase in the use of mechanistic mathematical models to explore complex systems such as cholesterol metabolism in a more integrated and nonreductionist fashion. Such models should be increasingly used to determine new targets for therapeutic intervention.

Amy Morgan wishes to thank the Faculty of Science and Engineering for funding her doctoral scholarship.

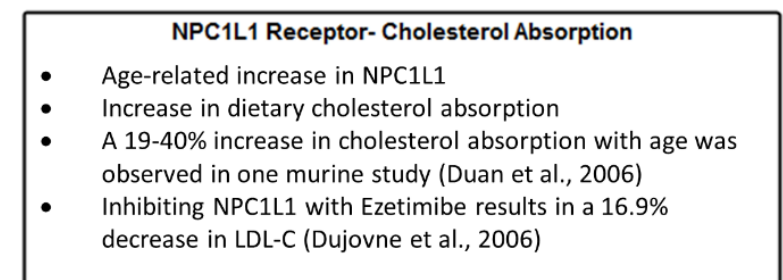

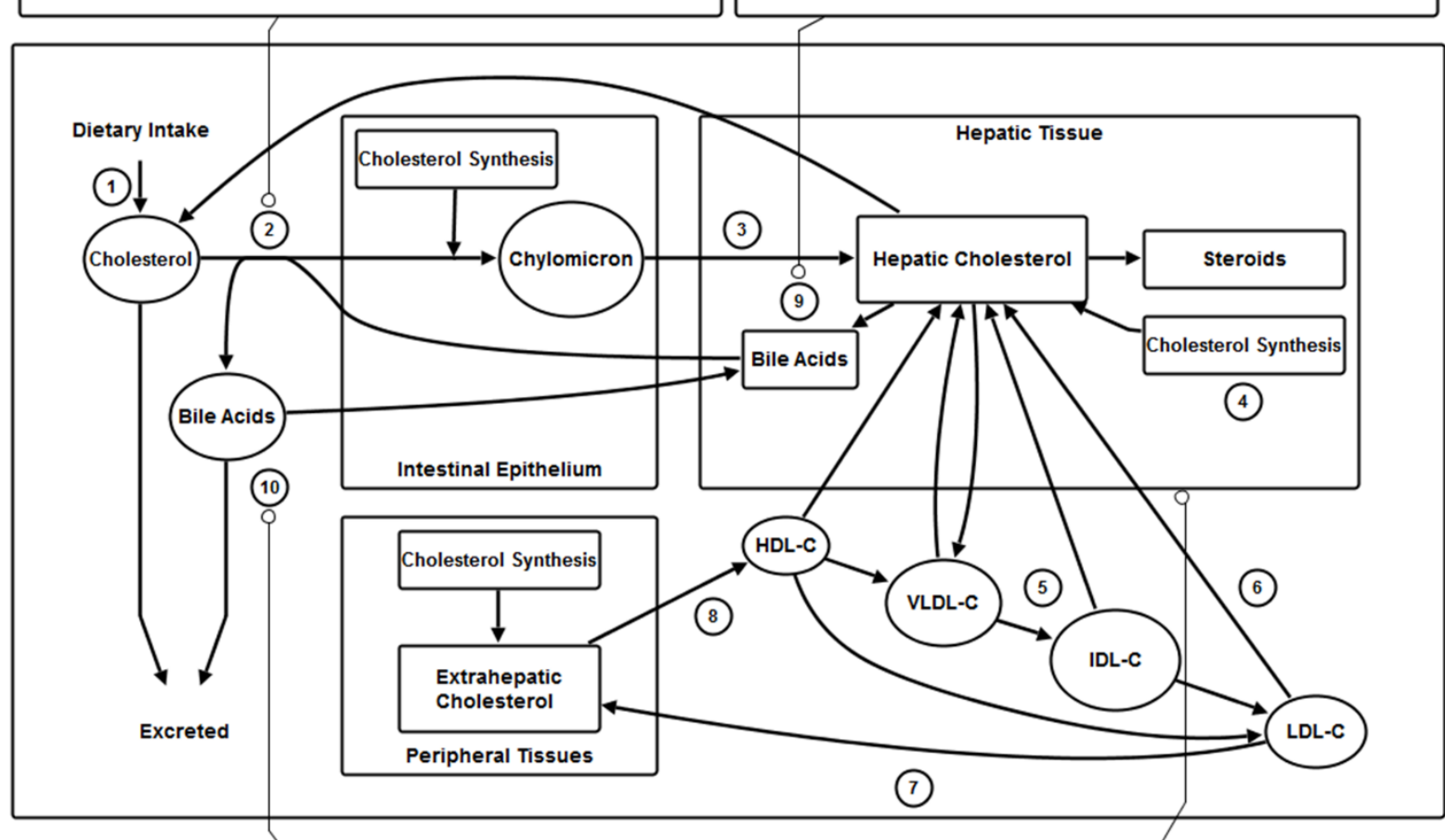

Bacterial Modification of Bile Acids

- Age-related decrease in $\mathrm{BSH}+$ species number and diversity e.g. Lactobacillus and Bifidobacterium (Hopkins \& Macfarlane, 2002)

- Decline in bile acid excretion and thus cholesterol utilization for the production of replacement bile acids (Uchida et al., 1996)

- Supplementation with probiotic strains reduces LDL-C (Al-Sheraji et al., 2012)

\section{Bile Acid Synthesis}

- Decline in CYP7AI expression with age, the key enzyme in bile acid synthesis

- Rise in cholesterol as a result of decreased demand for the synthesis of bile acids (Bertolotti et al., 2007)

- Estimated decrease of $60 \mathrm{mg} /$ day of cholesterol undergoing CYP7AI conversion every 10 years (Bertolotti et al., 1993) 
Figure 1. Overview of cholesterol metabolism and age associated changes to mechanisms. Briefly outlined is 1 ) ingestion of dietary cholesterol, 2) intestinal absorption, 3) chylomicron transport, 4) cholesterol biosynthesis, 5) VLDL-C production and hydrolysis to IDL-C and LDL-C, 6) hepatic uptake of LDL-C, 7) peripheral uptake of LDL-C, 8) reverse cholesterol transport, 9) bile acid synthesis, and 10) enterohepatic circulation of bile acids and bacterial modification. The age-related changes highlighted centre on some of the mechanisms responsible for the rise in LDL-C with age; the

911 increase in intestinal absorption of cholesterol, the reduction of bile acid synthesis, the decrease in LDL-C clearance, and the decrease in $\mathrm{BSH}^{+}$species in the digestive microbiome.

913

914

915 
Abbott, R.D., Garrison, R.J., Wilson, P.W., Epstein, F.H., Castelli, W.P., Feinleib, M., LaRue, C., 1983. Joint distribution of lipoprotein cholesterol classes. The Framingham study. Arteriosclerosis, Thrombosis, and Vascular Biology 3, 260-272.

Agerholm-Larsen, B., Tybjærg-Hansen, A., Schnohr, P., Steffensen, R., Nordestgaard, B.G., 2000. Common Cholesteryl Ester Transfer Protein Mutations, Decreased HDL Cholesterol, and Possible Decreased Risk of Ischemic Heart Disease: The Copenhagen City Heart Study. Circulation 102, 2197-2203.

Ajouz, H., Mukherji, D., Shamseddine, A., 2014. Secondary bile acids: an underrecognized cause of colon cancer. World Journal of Surgical Oncology 12, 164-164.

Al-Sheraji, S.H., Ismail, A., Manap, M.Y., Mustafa, S., Yusof, R.M., Hassan, F.A., 2012. Hypocholesterolaemic effect of yoghurt containing Bifidobacterium pseudocatenulatum $\mathrm{G} 4$ or Bifidobacterium longum BB536. Food Chem 135, 356-361.

Alang, N., Kelly, C.R., 2015. Weight Gain After Fecal Microbiota Transplantation. Open Forum Infectious Diseases 2.

Ambrose, J.A., Barua, R.S., 2004. The pathophysiology of cigarette smoking and cardiovascular disease: An update. Journal of the American College of Cardiology 43, 1731-1737.

Asselbergs, Folkert W., Guo, Y., van Iperen, Erik P., Sivapalaratnam, S., Tragante, V., Lanktree, Matthew B., Lange, Leslie A., Almoguera, B., Appelman, Yolande E., Barnard, J., Baumert, J., Beitelshees, Amber L., Bhangale, Tushar R., Chen, Y.-Der I., Gaunt, Tom R., Gong, Y., Hopewell, Jemma C., Johnson, T., Kleber, Marcus E., Langaee, Taimour Y., Li, M., Li, Yun R., Liu, K., McDonough, Caitrin W., Meijs, Matthijs F., Middelberg, Rita P., Musunuru, K., Nelson, Christopher P., O'Connell, Jeffery R., Padmanabhan, S., Pankow, James S., Pankratz, N., Rafelt, S., Rajagopalan, R., Romaine, Simon P., Schork, Nicholas J., Shaffer, J., Shen, H., Smith, Erin N., Tischfield, Sam E., van der Most, Peter J., van Vliet-Ostaptchouk, Jana V., Verweij, N., Volcik, Kelly A., Zhang, L., Bailey, Kent R., Bailey, Kristian M., Bauer, F., Boer, Jolanda M., Braund, Peter S., Burt, A., Burton, Paul R., Buxbaum, Sarah G., Chen, W., Cooper-DeHoff, Rhonda M., Cupples, L A., deJong, Jonas S., Delles, C., Duggan, D., Fornage, M., Furlong, Clement E., Glazer, N., Gums, John G., Hastie, C., Holmes, Michael V., Illig, T., Kirkland, Susan A., Kivimaki, M., Klein, R., Klein, Barbara E., Kooperberg, C., Kottke-Marchant, K., Kumari, M., LaCroix, Andrea Z., Mallela, L., Murugesan, G., Ordovas, J., Ouwehand, Willem H., Post, Wendy S., Saxena, R., Scharnagl, H., Schreiner, Pamela J., Shah, T., Shields, Denis C., Shimbo, D., Srinivasan, Sathanur R., Stolk, Ronald P., Swerdlow, Daniel I., Taylor, Herman A., Topol, Eric J., Toskala, E., van Pelt, Joost L., van Setten, J., Yusuf, S., Whittaker, John C., Zwinderman, A.H., LifeLines Cohort, S., Anand, Sonia S., Balmforth, Anthony J., Berenson, Gerald S., Bezzina, Connie R., Boehm, Bernhard O., Boerwinkle, E., Casas, Juan P., Caulfield, Mark J., Clarke, R., Connell, John M., Cruickshanks, Karen J., Davidson, Karina W., Day, Ian N., de Bakker, Paul I., Doevendans, Pieter A., Dominiczak, Anna F., Hall, Alistair S., Hartman, Catharina A., Hengstenberg, C., Hillege, Hans L., Hofker, Marten H., Humphries, Steve E., Jarvik, Gail P., Johnson, Julie A., Kaess, Bernhard M., Kathiresan, S., Koenig, W., Lawlor, Debbie A., März, W., Melander, O., Mitchell, Braxton D., Montgomery, Grant W., Munroe, Patricia B., Murray, Sarah S., Newhouse, Stephen J., Onland-Moret, N C., Poulter, N., Psaty, B., Redline, S., Rich, Stephen S., Rotter, Jerome I., Schunkert, H., Sever, P., Shuldiner, Alan R., Silverstein, Roy L., Stanton, A., Thorand, B., Trip, Mieke D., Tsai, Michael Y., van der Harst, P., van der Schoot, E., van der Schouw, Yvonne T., Verschuren, WM M., Watkins, H., Wilde, Arthur A., Wolffenbuttel, Bruce H., Whitfield, John B., Hovingh, G K., Ballantyne, Christie M., Wijmenga, C., Reilly, Muredach P., Martin, Nicholas G., Wilson, James G., Rader, Daniel J., Samani, Nilesh J., Reiner, Alex P., Hegele, Robert A., Kastelein, John J., Hingorani, Aroon D., Talmud, Philippa J., Hakonarson, H., Elbers, Clara C., Keating, Brendan J., Drenos, F., 2012. Large-Scale Gene-Centric Meta-analysis across 32 Studies Identifies Multiple Lipid Loci. American Journal of Human Genetics 91, 823-838. 
Atzmon, G., Rincon, M., Rabizadeh, P., Barzilai, N., 2005. Biological evidence for inheritance of exceptional longevity. Mech Ageing Dev 126, 341-345.

Baidya, S., Zeng, Q., 2005. Helper T cells and atherosclerosis: the cytokine web. Postgraduate Medical Journal 81, 746-752.

Baigent, C., Blackwell, L., Emberson, J., Holland, L.E., Reith, C., Bhala, N., Peto, R., Barnes, E.H., Keech, A., Simes, J., Collins, R., 2010. Efficacy and safety of more intensive lowering of LDL cholesterol: a meta-analysis of data from 170,000 participants in 26 randomised trials. Lancet 376, 1670-1681.

Barber, M.J., Mangravite, L.M., Hyde, C.L., Chasman, D.I., Smith, J.D., McCarty, C.A., Li, X., Wilke, R.A., Rieder, M.J., Williams, P.T., Ridker, P.M., Chatterjee, A., Rotter, J.I., Nickerson, D.A., Stephens, M., Krauss, R.M., 2010. Genome-Wide Association of Lipid-Lowering Response to Statins in Combined Study Populations. PLoS ONE 5, e9763.

Barzilai, N., Atzmon, G., Derby, C.A., Bauman, J.M., Lipton, R.B., 2006. A genotype of exceptional longevity is associated with preservation of cognitive function. Neurology 67, 2170-2175.

Barzilai, N., Atzmon, G., Schechter, C., Schaefer, E.J., Cupples, A.L., Lipton, R., Cheng, S., Shuldiner, A.R., 2003. Unique lipoprotein phenotype and genotype associated with exceptional longevity. JAMA 290, 2030-2040.

Barzilai, N., Gabriely, I., Gabriely, M., lankowitz, N., Sorkin, J.D., 2001. Offspring of centenarians have a favorable lipid profile. J Am Geriatr Soc 49, 76-79.

Barzilai, N., Huffman, D.M., Muzumdar, R.H., Bartke, A., 2012. The critical role of metabolic pathways in aging. Diabetes 61, 1315-1322.

Batta, A.K., Salen, G., Rapole, K.R., Batta, M., Batta, P., Alberts, D., Earnest, D., 1999. Highly simplified method for gas-liquid chromatographic quantitation of bile acids and sterols in human stool. Journal of lipid research 40, 1148-1154.

Begley, M., Hill, C., Gahan, C.G.M., 2006. Bile Salt Hydrolase Activity in Probiotics. Applied and Environmental Microbiology 72, 1729-1738.

Benetou, V., Trichopoulou, A., Orfanos, P., Naska, A., Lagiou, P., Boffetta, P., Trichopoulos, D., 2008. Conformity to traditional Mediterranean diet and cancer incidence: the Greek EPIC cohort. Br J Cancer 99, 191-195.

Bennet, A.M., Di Angelantonio, E., Ye, Z., Wensley, F., Dahlin, A., Ahlbom, A., Keavney, B., Collins, R., Wiman, B., de Faire, U., Danesh, J., 2007. Association of apolipoprotein E genotypes with lipid levels and coronary risk. JAMA 298, 1300-1311.

Bentzon, J.F., Otsuka, F., Virmani, R., Falk, E., 2014. Mechanisms of Plaque Formation and Rupture. Circulation Research 114, 1852-1866.

Berthiaume, J.M., Wallace, K.B., 2007. Adriamycin-induced oxidative mitochondrial cardiotoxicity. Cell Biology and Toxicology 23, 15-25.

Bertolotti, M., Abate, N., Bertolotti, S., Loria, P., Concari, M., Messora, R., Carubbi, F., Pinetti, A., Carulli, N., 1993. Effect of aging on cholesterol 7 alpha-hydroxylation in humans. Journal of lipid research 34, 1001-1007.

Bertolotti, M., Gabbi, C., Anzivino, C., Crestani, M., Mitro, N., Del Puppo, M., Godio, C., De Fabiani, E., Macchioni, D., Carulli, L., Rossi, A., Ricchi, M., Loria, P., Carulli, N., 2007. Age-related changes in bile acid synthesis and hepatic nuclear receptor expression. Eur J Clin Invest 37, 501-508.

Betters, J.L., Yu, L., 2010. NPC1L1 and cholesterol transport. FEBS Letters 584, 2740-2747.

Bhattacharya, B.S., Sweby, P.K., Minihane, A.M., Jackson, K.G., Tindall, M.J., 2014. A mathematical model of the sterol regulatory element binding protein 2 cholesterol biosynthesis pathway. J Theor Biol 349, 150-162.

Biagi, E., Candela, M., Fairweather-Tait, S., Franceschi, C., Brigidi, P., 2012. Ageing of the human metaorganism: the microbial counterpart. Age 34, 247-267.

Biagi, E., Nylund, L., Candela, M., Ostan, R., Bucci, L., Pini, E., Nikkïla, J., Monti, D., Satokari, R., Franceschi, C., Brigidi, P., De Vos, W., 2010. Through Ageing, and Beyond: Gut Microbiota and Inflammatory Status in Seniors and Centenarians. PLoS ONE 5, e10667. 
Biswas, H.H., Gordon, A., Nunez, A., Perez, M.A., Balmaseda, A., Harris, E., 2015. Lower Low-Density Lipoprotein Cholesterol Levels Are Associated with Severe Dengue Outcome. PLoS Negl Trop Dis 9, e0003904.

Bloch, K., 1965. The Biological Synthesis of Cholesterol. Science 150, 19-28.

Boge, T., Remigy, M., Vaudaine, S., Tanguy, J., Bourdet-Sicard, R., van der Werf, S., 2009. A probiotic fermented dairy drink improves antibody response to influenza vaccination in the elderly in two randomised controlled trials. Vaccine 27, 5677-5684.

Bosner, M.S., Lange, L.G., Stenson, W.F., Ostlund, R.E., 1999. Percent cholesterol absorption in normal women and men quantified with dual stable isotopic tracers and negative ion mass spectrometry. Journal of lipid research 40, 302-308.

Buijsse, B., Feskens, E.J., Kwape, L., Kok, F.J., Kromhout, D., 2008. Both alpha- and beta-carotene, but not tocopherols and vitamin C, are inversely related to 15 -year cardiovascular mortality in Dutch elderly men. J Nutr 138, 344-350.

Callegari, E., Norata, G.D., Inoue, H., Catapano, A.L., 2006. Oxidized-HDL3 modulates the expression of Cox-2 in human endothelial cells. Int J Mol Med 18, 209-213.

Candela, M., Biagi, E., Brigidi, P., O'Toole, P.W., De Vos, W.M., 2014. Maintenance of a healthy trajectory of the intestinal microbiome during aging: A dietary approach. Mechanisms of Ageing and Development 136-137, 70-75.

Capuron, L., Schroecksnadel, S., Feart, C., Aubert, A., Higueret, D., Barberger-Gateau, P., Laye, S., Fuchs, D., 2011. Chronic low-grade inflammation in elderly persons is associated with altered tryptophan and tyrosine metabolism: role in neuropsychiatric symptoms. Biol Psychiatry 70, 175-182.

Cefalu, A.B., Noto, D., Magnolo, L., Pinotti, E., Gomaraschi, M., Martini, S., Vigna, G.B., Calabresi, L., Tarugi, P., Averna, M.R., 2009. Novel mutations of CETP gene in Italian subjects with hyperalphalipoproteinemia. Atherosclerosis 204, 202-207.

Chang, T.-Y., Li, B.-L., Chang, C.C.Y., Urano, Y., 2009. Acyl-coenzyme A:cholesterol acyltransferases. American Journal of Physiology - Endocrinology and Metabolism 297, E1-E9.

Chapman, M.J., Le Goff, W., Guerin, M., Kontush, A., 2010. Cholesteryl ester transfer protein: at the heart of the action of lipid-modulating therapy with statins, fibrates, niacin, and cholesteryl ester transfer protein inhibitors. Eur Heart J 31, 149-164.

Chasman, D.I., Posada, D., Subrahmanyan, L., Cook, N.R., Stanton, Jr, V.P., Ridker, P., 2004. PHarmacogenetic study of statin therapy and cholesterol reduction. JAMA 291, 2821-2827.

Chistiakov, D.A., Bobryshev, Y.V., Kozarov, E., Sobenin, I.A., Orekhov, A.N., 2015. Role of gut microbiota in the modulation of atherosclerosis-associated immune response. Frontiers in Microbiology 6, 671.

Claesson, M.J., Cusack, S., O'Sullivan, O., Greene-Diniz, R., de Weerd, H., Flannery, E., Marchesi, J.R., Falush, D., Dinan, T., Fitzgerald, G., Stanton, C., van Sinderen, D., O'Connor, M., Harnedy, N., O'Connor, K., Henry, C., O'Mahony, D., Fitzgerald, A.P., Shanahan, F., Twomey, C., Hill, C., Ross, R.P., O'Toole, P.W., 2011. Composition, variability, and temporal stability of the intestinal microbiota of the elderly. Proceedings of the National Academy of Sciences of the United States of America 108, 4586-4591.

Claesson, M.J., Jeffery, I.B., Conde, S., Power, S.E., O/'Connor, E.M., Cusack, S., Harris, H.M.B., Coakley, M., Lakshminarayanan, B., O/'Sullivan, O., Fitzgerald, G.F., Deane, J., O/'Connor, M., Harnedy, N., O/'Connor, K., O/'Mahony, D., van Sinderen, D., Wallace, M., Brennan, L., Stanton, C., Marchesi, J.R., Fitzgerald, A.P., Shanahan, F., Hill, C., Ross, R.P., O/'Toole, P.W., 2012. Gut microbiota composition correlates with diet and health in the elderly. Nature 488, 178-184.

Cohen, J.C., Pertsemlidis, A., Fahmi, S., Esmail, S., Vega, G.L., Grundy, S.M., Hobbs, H.H., 2006. Multiple rare variants in NPC1L1 associated with reduced sterol absorption and plasma lowdensity lipoprotein levels. Proc Natl Acad Sci U S A 103, 1810-1815. 
Colman, R.J., Beasley, T.M., Kemnitz, J.W., Johnson, S.C., Weindruch, R., Anderson, R.M., 2014. Caloric restriction reduces age-related and all-cause mortality in rhesus monkeys. Nature Communications 5, 3557.

Colotti, C., Cavallini, G., Vitale, R.L., Donati, A., Maltinti, M., Del Ry, S., Bergamini, E., Giannessi, D., 2005. Effects of Aging and Anti-Aging Caloric Restrictions on Carbonyl and Heat Shock Protein Levels and Expression. Biogerontology 6, 397-406.

Cooney, M.T., Dudina, A., De Bacquer, D., Wilhelmsen, L., Sans, S., Menotti, A., De Backer, G., Jousilahti, P., Keil, U., Thomsen, T., Whincup, P., Graham, I.M., 2009. HDL cholesterol protects against cardiovascular disease in both genders, at all ages and at all levels of risk. Atherosclerosis 206, 611-616.

Cooper, A.D., 1997. Hepatic uptake of chylomicron remnants. Journal of lipid research 38, $2173-$ 2192.

Cui, Q., Ju, X., Yang, T., Zhang, M., Tang, W., Chen, Q., Hu, Y., Haas, J.V., Troutt, J.S., Pickard, R.T., Darling, R., Konrad, R.J., Zhou, H., Cao, G., 2010. Serum PCSK9 is associated with multiple metabolic factors in a large Han Chinese population. Atherosclerosis 213, 632-636.

Daoud, M.S., Ataya, F.S., Fouad, D., Alhazzani, A., Shehata, A.I., Al-Jafari, A.A., 2013. Associations of three lipoprotein lipase gene polymorphisms, lipid profiles and coronary artery disease. Biomedical Reports 1, 573-582.

David, L.A., Maurice, C.F., Carmody, R.N., Gootenberg, D.B., Button, J.E., Wolfe, B.E., Ling, A.V., Devlin, A.S., Varma, Y., Fischbach, M.A., Biddinger, S.B., Dutton, R.J., Turnbaugh, P.J., 2014. Diet rapidly and reproducibly alters the human gut microbiome. Nature 505, 559-563.

Dawson, P.A., 2011. Role of the Intestinal Bile Acid Transporters in Bile Acid and Drug Disposition. Handbook of experimental pharmacology, 169-203.

de Beer, F., Stalenhoef, A.F.H., Hoogerbrugge, N., Kastelein, J.J.P., Gevers Leuven, J.A., van Duijn, C.M., Havekes, L.M., Smelt, A.H.M., 2002. Expression of Type III Hyperlipoproteinemia in Apolipoprotein E2 (Arg158 $\rightarrow$ Cys) Homozygotes Is Associated With Hyperinsulinemia. Arteriosclerosis, Thrombosis, and Vascular Biology 22, 294-299.

de Lorgeril, M., Salen, P., Martin, J.-L., Monjaud, I., Delaye, J., Mamelle, N., 1999. Mediterranean Diet, Traditional Risk Factors, and the Rate of Cardiovascular Complications After Myocardial Infarction: Final Report of the Lyon Diet Heart Study. Circulation 99, 779-785.

de Magalhães, J.P., Wuttke, D., Wood, S.H., Plank, M., Vora, C., 2012. Genome-Environment Interactions That Modulate Aging: Powerful Targets for Drug Discovery. Pharmacological Reviews 64, 88-101.

Dewald, O., Zymek, P., Winkelmann, K., Koerting, A., Ren, G., Abou-Khamis, T., Michael, L.H., Rollins, B.J., Entman, M.L., Frangogiannis, N.G., 2005. CCL2/Monocyte Chemoattractant Protein-1 Regulates Inflammatory Responses Critical to Healing Myocardial Infarcts. Circulation Research 96, 881-889.

Dong, L.M., Weisgraber, K.H., 1996. Human apolipoprotein E4 domain interaction. Arginine 61 and glutamic acid 255 interact to direct the preference for very low density lipoproteins. J Biol Chem 271, 19053-19057.

Duan, L.P., Wang, H.H., Ohashi, A., Wang, D.Q., 2006. Role of intestinal sterol transporters Abcg5, Abcg8, and Npc111 in cholesterol absorption in mice: gender and age effects. Am J Physiol Gastrointest Liver Physiol 290, G269-276.

Dubuc, G., Tremblay, M., Pare, G., Jacques, H., Hamelin, J., Benjannet, S., Boulet, L., Genest, J., Bernier, L., Seidah, N.G., Davignon, J., 2010. A new method for measurement of total plasma PCSK9: clinical applications. Journal of lipid research 51, 140-149.

Edwards, I.J., Rudel, L.L., Terry, J.G., Kemnitz, J.W., Weindruch, R., Cefalu, W.T., 1998. Caloric restriction in rhesus monkeys reduces low density lipoprotein interaction with arterial proteoglycans. The journals of gerontology. Series A, Biological sciences and medical sciences 53, B443-448. 
Einarsson, K., Nilsell, K., Leijd, B., Angelin, B., 1985. Influence of age on secretion of cholesterol and synthesis of bile acids by the liver. N Engl J Med 313, 277-282.

Engelborghs, S., Dermaut, B., Goeman, J., Saerens, J., Marien, P., Pickut, B., Van den Broeck, M., Serneels, S., Cruts, M., Van Broeckhoven, C., De Deyn, P.P., 2003. Prospective Belgian study of neurodegenerative and vascular dementia: APOE genotype effects. Journal of Neurology, Neurosurgery, and Psychiatry 74, 1148-1151.

Enrique Salcedo-Sora, J., Mc Auley, M.T., 2016. A mathematical model of microbial folate biosynthesis and utilisation: implications for antifolate development. Molecular bioSystems 12, 923-933.

Ericsson, S., Eriksson, M., Vitols, S., Einarsson, K., Berglund, L., Angelin, B., 1991. Influence of age on the metabolism of plasma low density lipoproteins in healthy males. Journal of Clinical Investigation 87, 591-596.

Estruch, R., Ros, E., Salas-Salvadó, J., Covas, M.-I., Corella, D., Arós, F., Gómez-Gracia, E., RuizGutiérrez, V., Fiol, M., Lapetra, J., Lamuela-Raventos, R.M., Serra-Majem, L., Pintó, X., Basora, J., Muñoz, M.A., Sorlí, J.V., Martínez, J.A., Martínez-González, M.A., 2013. Primary Prevention of Cardiovascular Disease with a Mediterranean Diet. New England Journal of Medicine 368, 1279-1290.

Everard, A., Lazarevic, V., Gaia, N., Johansson, M., Stahlman, M., Backhed, F., Delzenne, N.M., Schrenzel, J., Francois, P., Cani, P.D., 2014. Microbiome of prebiotic-treated mice reveals novel targets involved in host response during obesity. ISME J 8, 2116-2130.

Fan, Y.-M., Laaksonen, R., Janatuinen, T., Vesalainen, R., Laine, H., Raitakari, O.T., Nuutila, P., Knuuti, J., Rontu, R., Lehtimäki, T., 2006. The influence of hepatic lipase C-480T polymorphism on coronary flow reserve in young men is independent of the plasma cholesterol level. Atherosclerosis 188, 391-397.

Fernandez-Real, J.M., Serino, M., Blasco, G., Puig, J., Daunis, I.E.J., Ricart, W., Burcelin, R., FernandezAranda, F., Portero-Otin, M., 2015. Gut microbiota interacts with brain microstructure and function. J Clin Endocrinol Metab, jc20153076.

Fernandez, M.L., West, K.L., 2005. Mechanisms by which Dietary Fatty Acids Modulate Plasma Lipids1. The Journal of Nutrition 135, 2075-2078.

Ferrara, A., Barrett-Connor, E., Shan, J., 1997. Total, LDL, and HDL cholesterol decrease with age in older men and women. The Rancho Bernardo Study 1984-1994. Circulation 96, 37-43.

Field, F.J., Born, E., Mathur, S.N., 2004. Stanol esters decrease plasma cholesterol independently of intestinal $A B C$ sterol transporters and Niemann-Pick C1-like 1 protein gene expression. Journal of lipid research 45, 2252-2259.

Fontana, L., Meyer, T.E., Klein, S., Holloszy, J.O., 2004. Long-term calorie restriction is highly effective in reducing the risk for atherosclerosis in humans. Proceedings of the National Academy of Sciences of the United States of America 101, 6659-6663.

Fu, J., Bonder, M.J., Cenit, M.C., Tigchelaar, E., Maatman, A., Dekens, J.A.M., Brandsma, E., Marczynska, J., Imhann, F., Weersma, R.K., Franke, L., Poon, T.W., Xavier, R.J., Gevers, D., Hofker, M.H., Wijmenga, C., Zhernakova, A., 2015. The Gut Microbiome Contributes to a Substantial Proportion of the Variation in Blood Lipids. Circulation Research.

Fu, Z.D., Csanaky, I.L., Klaassen, C.D., 2012. Gender-Divergent Profile of Bile Acid Homeostasis during Aging of Mice. PLoS ONE 7, e32551.

Garatachea, N., Emanuele, E., Calero, M., Fuku, N., Arai, Y., Abe, Y., Murakami, H., Miyachi, M., Yvert, T., Verde, Z., Zea, M.A., Venturini, L., Santiago, C., Santos-Lozano, A., Rodríguez-Romo, G., Ricevuti, G., Hirose, N., Rábano, A., Lucia, A., 2014. ApoE gene and exceptional longevity: Insights from three independent cohorts. Experimental Gerontology 53, 16-23.

Gérard, P., 2014. Metabolism of Cholesterol and Bile Acids by the Gut Microbiota. Pathogens 3, 1424.

Goldberg, I.J., Eckel, R.H., Abumrad, N.A., 2009. Regulation of fatty acid uptake into tissues: lipoprotein lipase- and CD36-mediated pathways. Journal of lipid research 50, S86-S90. 
Gould, A.L., Davies, G.M., Alemao, E., Yin, D.D., Cook, J.R., 2007. Cholesterol reduction yields clinical benefits: meta-analysis including recent trials. Clinical Therapeutics 29, 778-794.

Gredilla, R., Sanz, A., Lopez-Torres, M., Barja, G., 2001. Caloric restriction decreases mitochondrial free radical generation at complex I and lowers oxidative damage to mitochondrial DNA in the rat heart. The FASEB Journal 15, 1589-1591.

Gregory, J.C., Buffa, J.A., Org, E., Wang, Z., Levison, B.S., Zhu, W., Wagner, M.A., Bennett, B.J., Li, L., DiDonato, J.A., Lusis, A.J., Hazen, S.L., 2015. Transmission of atherosclerosis susceptibility with gut microbial transplantation. J Biol Chem 290, 5647-5660.

Groen, A.K., Oude Elferink, R.P., Verkade, H.J., Kuipers, F., 2004. The ins and outs of reverse cholesterol transport. Annals of medicine 36, 135-145.

Guarente, L., 2013. Calorie restriction and sirtuins revisited. Genes \& development 27, 2072-2085.

Guthikonda, S., Haynes, W.G., 2006. Homocysteine: role and implications in atherosclerosis. Curr Atheroscler Rep 8, 100-106.

Gylling, H., 2004. Cholesterol metabolism and its implications for therapeutic interventions in patients with hypercholesterolaemia. International Journal of Clinical Practice 58, 859-866.

Hansson, G.K., Hermansson, A., 2011. The immune system in atherosclerosis. Nat Immunol 12, 204212.

Hara, H., Haga, S., Aoyama, Y., Kiriyama, S., 1999. Short-chain fatty acids suppress cholesterol synthesis in rat liver and intestine. J Nutr 129, 942-948.

Harman, D., 1956. Aging: a theory based on free radical and radiation chemistry. Journal of gerontology 11, 298-300.

Harman, D., 2009. Origin and evolution of the free radical theory of aging: a brief personal history, 1954-2009. Biogerontology 10, 773-781.

Hasan, S.T., Zingg, J.M., Kwan, P., Noble, T., Smith, D., Meydani, M., 2014. Curcumin modulation of high fat diet-induced atherosclerosis and steatohepatosis in LDL receptor deficient mice. Atherosclerosis 232, 40-51.

Havel, R.J., 1984. The formation of LDL: mechanisms and regulation. Journal of lipid research 25, 1570-1576.

Hayashi, H., Sakamoto, M., Kitahara, M., Benno, Y., 2003. Molecular analysis of fecal microbiota in elderly individuals using 16S rDNA library and T-RFLP. Microbiol Immunol 47, 557-570.

Heilbronn, L.K., de Jonge, L., Frisard, M.I., DeLany, J.P., Meyer, D.E.L., Rood, J., Nguyen, T., Martin, C.K., Volaufova, J., Most, M.M., Greenway, F.L., Smith, S.R., Williamson, D.A., Deutsch, W.A., Ravussin, E., 2006. Effect of 6-mo. calorie restriction on biomarkers of longevity, metabolic adaptation and oxidative stress in overweight subjects. JAMA : the journal of the American Medical Association 295, 1539-1548.

Henderson, L., Gregory, J., Irving, K., Swan, G., 2003. The National Diet \& Nutrition Survey: adults aged 19 to 64 years, Office for National Statistics.

Herron, K.L., Vega-Lopez, S., Conde, K., Ramjiganesh, T., Shachter, N.S., Fernandez, M.L., 2003. Men classified as hypo- or hyperresponders to dietary cholesterol feeding exhibit differences in lipoprotein metabolism. J Nutr 133, 1036-1042.

Hippe, B., Zwielehner, J., Liszt, K., Lassl, C., Unger, F., Haslberger, A.G., 2011. Quantification of butyryl CoA:acetate CoA-transferase genes reveals different butyrate production capacity in individuals according to diet and age. FEMS Microbiol Lett 316, 130-135.

Hirano, K., Yamashita, S., Nakajima, N., Arai, T., Maruyama, T., Yoshida, Y., Ishigami, M., Sakai, N., Kameda-Takemura, K., Matsuzawa, Y., 1997. Genetic cholesteryl ester transfer protein deficiency is extremely frequent in the Omagari area of Japan. Marked hyperalphalipoproteinemia caused by CETP gene mutation is not associated with longevity. Arterioscler Thromb Vasc Biol 17, 1053-1059.

Hollander, D., Morgan, D., 1979. Increase in cholesterol intestinal absorption with aging in the rat. Exp Gerontol 14, 201-204. 
Hopkins, M.J., Macfarlane, G.T., 2002. Changes in predominant bacterial populations in human faeces with age and with Clostridium difficile infection. J Med Microbiol 51, 448-454.

Horakova, D., Kyr, M., Havrdova, E., Dolezal, O., Lelkova, P., Pospisilova, L., Bergsland, N., Dwyer, M.G., Cox, J.L., Hussein, S., Seidl, Z., Vaneckova, M., Krasensky, J., Zivadinov, R., 2010. Apolipoprotein E epsilon4-positive multiple sclerosis patients develop more gray-matter and whole-brain atrophy: a 15-year disease history model based on a 4-year longitudinal study. Folia Biol (Praha) 56, 242-251.

Horton, J.D., Goldstein, J.L., Brown, M.S., 2002. SREBPs: activators of the complete program of cholesterol and fatty acid synthesis in the liver. The Journal of clinical investigation 109, 1125-1131.

Hübner, K., Schwager, T., Winkler, K., Reich, J.-G., Holzhütter, H.-G., 2008. Computational Lipidology: Predicting Lipoprotein Density Profiles in Human Blood Plasma. PLoS Comput Biol 4, e1000079.

Hucka, M., Finney, A., Sauro, H.M., Bolouri, H., Doyle, J.C., Kitano, H., Arkin, A.P., Bornstein, B.J., Bray, D., Cornish-Bowden, A., Cuellar, A.A., Dronov, S., Gilles, E.D., Ginkel, M., Gor, V., Goryanin, II, Hedley, W.J., Hodgman, T.C., Hofmeyr, J.H., Hunter, P.J., Juty, N.S., Kasberger, J.L., Kremling, A., Kummer, U., Le Novere, N., Loew, L.M., Lucio, D., Mendes, P., Minch, E., Mjolsness, E.D., Nakayama, Y., Nelson, M.R., Nielsen, P.F., Sakurada, T., Schaff, J.C., Shapiro, B.E., Shimizu, T.S., Spence, H.D., Stelling, J., Takahashi, K., Tomita, M., Wagner, J., Wang, J., 2003. The systems biology markup language (SBML): a medium for representation and exchange of biochemical network models. Bioinformatics 19, 524-531.

Huebbe, P., Nebel, A., Siegert, S., Moehring, J., Boesch-Saadatmandi, C., Most, E., Pallauf, J., Egert, S., Muller, M.J., Schreiber, S., Nothlings, U., Rimbach, G., 2011. APOE epsilon4 is associated with higher vitamin D levels in targeted replacement mice and humans. FASEB J 25, 3262-3270.

Ikeda, I., Matsuoka, R., Hamada, T., Mitsui, K., Imabayashi, S., Uchino, A., Sato, M., Kuwano, E., Itamura, T., Yamada, K., Tanaka, K., Imaizumi, K., 2002. Cholesterol esterase accelerates intestinal cholesterol absorption. Biochimica et Biophysica Acta (BBA) - General Subjects 1571, 34-44.

Iqbal, J., Hussain, M.M., 2009. Intestinal lipid absorption. American Journal of Physiology Endocrinology and Metabolism 296, E1183-E1194.

Ishibashi, S., Brown, M.S., Goldstein, J.L., Gerard, R.D., Hammer, R.E., Herz, J., 1993. Hypercholesterolemia in low density lipoprotein receptor knockout mice and its reversal by adenovirus-mediated gene delivery. Journal of Clinical Investigation 92, 883-893.

Istvan, E.S., Deisenhofer, J., 2001. Structural Mechanism for Statin Inhibition of HMG-CoA Reductase. Science 292, 1160-1164.

Jamil, H., Dickson, J.K., Chu, C.-H., Lago, M.W., Rinehart, J.K., Biller, S.A., Gregg, R.E., Wetterau, J.R., 1995. Microsomal Triglyceride Transfer Protein: SPECIFICITY OF LIPID BINDING AND TRANSPORT. Journal of Biological Chemistry 270, 6549-6554.

Jenkins, D.A., Jones, P.H., Lamarche, B., et al., 2011. Effect of a dietary portfolio of cholesterollowering foods given at 2 levels of intensity of dietary advice on serum lipids in hyperlipidemia: A randomized controlled trial. JAMA 306, 831-839.

Jenkins, D.J.A., Jones, P.J., Frohlich, J., Lamarche, B., Ireland, C., Nishi, S.K., Srichaikul, K., Galange, P., Pellini, C., Faulkner, D., de Souza, R.J., Sievenpiper, J.L., Mirrahimi, A., Jayalath, V.H., Augustin, L.S., Bashyam, B., Leiter, L.A., Josse, R., Couture, P., Ramprasath, V., Kendall, C.W.C., 2015. The effect of a dietary portfolio compared to a DASH-type diet on blood pressure. Nutrition, Metabolism and Cardiovascular Diseases.

Johnson, S.C., Rabinovitch, P.S., Kaeberlein, M., 2013. mTOR is a key modulator of ageing and agerelated disease. Nature 493, 338-345.

Joyce, S.A., MacSharry, J., Casey, P.G., Kinsella, M., Murphy, E.F., Shanahan, F., Hill, C., Gahan, C.G.M., 2014. Regulation of host weight gain and lipid metabolism by bacterial bile acid modification in the gut. Proceedings of the National Academy of Sciences 111, 7421-7426. 
Kandola, K., Bowman, A., Birch-Machin, M.A., 2015. Oxidative stress - a key emerging impact factor in health, ageing, lifestyle and aesthetics. Int J Cosmet Sci 37 Suppl 2, 1-8.

Keith, M., Kuliszewski, M.A., Liao, C., Peeva, V., Ahmed, M., Tran, S., Sorokin, K., Jenkins, D.J., Errett, L., Leong-Poi, H., 2015. A modified portfolio diet complements medical management to reduce cardiovascular risk factors in diabetic patients with coronary artery disease. Clinical Nutrition 34, 541-548.

Kerenyi, L., Mihalka, L., Csiba, L., Bacso, H., Bereczki, D., 2006. Role of hyperlipidemia in atherosclerotic plaque formation in the internal carotid artery. J Clin Ultrasound 34, 283288.

Kervizic, G., Corcos, L., 2008. Dynamical modeling of the cholesterol regulatory pathway with Boolean networks. BMC Syst Biol 2, 99.

Kiliaan, A.J., Saunders, P.R., Bijlsma, P.B., Berin, M.C., Taminiau, J.A., Groot, J.A., Perdue, M.H., 1998. Stress stimulates transepithelial macromolecular uptake in rat jejunum. Am J Physiol 275, G1037-1044.

Kilner, J., Corfe, B.M., McAuley, M.T., Wilkinson, S.J., 2016. A deterministic oscillatory model of microtubule growth and shrinkage for differential actions of short chain fatty acids. Molecular bioSystems 12, 93-101.

Koeth, R.A., Wang, Z., Levison, B.S., Buffa, J.A., Org, E., Sheehy, B.T., Britt, E.B., Fu, X., Wu, Y., Li, L., Smith, J.D., DiDonato, J.A., Chen, J., Li, H., Wu, G.D., Lewis, J.D., Warrier, M., Brown, J.M., Krauss, R.M., Tang, W.H.W., Bushman, F.D., Lusis, A.J., Hazen, S.L., 2013. Intestinal microbiota metabolism of I-carnitine, a nutrient in red meat, promotes atherosclerosis. Nat Med 19, 576-585.

Koropatnick, T.A., Kimbell, J., Chen, R., Grove, J.S., Donlon, T.A., Masaki, K.H., Rodriguez, B.L., Willcox, B.J., Yano, K., Curb, J.D., 2008. A prospective study of high-density lipoprotein cholesterol, cholesteryl ester transfer protein gene variants, and healthy aging in very old Japanese-american men. The journals of gerontology. Series A, Biological sciences and medical sciences 63, 1235-1240.

Korporaal, S.J.A., Van Eck, M., Adelmeijer, J., ljsseldijk, M., Out, R., Lisman, T., Lenting, P.J., Van Berkel, T.J.C., Akkerman, J.-W.N., 2007. Platelet Activation by Oxidized Low Density Lipoprotein Is Mediated by Cd36 and Scavenger Receptor-A. Arteriosclerosis, Thrombosis, and Vascular Biology 27, 2476-2483.

Kovacs, K.A., Pamer, Z., Kovacs, A., Fekete, S., Miseta, A., Kovacs, B., Kovacs, G.L., 2007. Association of apolipoprotein $\mathrm{E}$ polymorphism with age-related macular degeneration and Alzheimer's disease in south-western Hungary. Ideggyogy Sz 60, 169-172.

Kowala, M.C., Recce, R., Beyer, S., Gu, C., Valentine, M., 2000. Characterization of atherosclerosis in LDL receptor knockout mice: macrophage accumulation correlates with rapid and sustained expression of aortic MCP-1/JE. Atherosclerosis 149, 323-330.

Kromhout, D., Menotti, A., Bloemberg, B., Aravanis, C., Blackburn, H., Buzina, R., Dontas, A.S., Fidanza, F., Giampaoli, S., Jansen, A., et al., 1995. Dietary saturated and trans fatty acids and cholesterol and 25-year mortality from coronary heart disease: the Seven Countries Study. Prev Med 24, 308-315.

Kulanuwat, S., Tungtrongchitr, R., Billington, D., Davies, I.G., 2015. Prevalence of plasma small dense LDL is increased in obesity in a Thai population. Lipids Health Dis. 14, 8.

Larson-Meyer, D.E., Heilbronn, L.K., Redman, L.M., Newcomer, B.R., Frisard, M.I., Anton, S., Smith, S.R., Maplstat, A.A., Ravussin, E., Pennington, C.T., 2006. Effect of Calorie Restriction With or Without Exercise on Insulin Sensitivity, $\beta$-Cell Function, Fat Cell Size, and Ectopic Lipid in Overweight Subjects. Diabetes care 29, 1337-1344.

Larson, I., Hoffmann, M.M., Ordovas, J.M., Schaefer, E.J., März, W., Kreuzer, J., 1999. The Lipoprotein Lipase HindIII Polymorphism: Association with Total Cholesterol and LDL-Cholesterol, but not with HDL and Triglycerides in 342 Females. Clinical Chemistry 45, 963-968. 
Larson, I.A., Ordovas, J.M., DeLuca, C., Barnard, J.R., Feussner, G., Schaefer, E.J., 2000. Association of apolipoprotein (Apo)E genotype with plasma apo E levels. Atherosclerosis 148, 327-335.

Law, M., 2000. Plant sterol and stanol margarines and health. BMJ (Clinical research ed.) 320, 861864.

Le Novere, N., Bornstein, B., Broicher, A., Courtot, M., Donizelli, M., Dharuri, H., Li, L., Sauro, H., Schilstra, M., Shapiro, B., Snoep, J.L., Hucka, M., 2006. BioModels Database: a free, centralized database of curated, published, quantitative kinetic models of biochemical and cellular systems. Nucleic Acids Res 34, D689-691.

Li, J.J., Chen, J.L., 2005. Inflammation may be a bridge connecting hypertension and atherosclerosis. Med Hypotheses 64, 925-929.

Li, X., Zhang, S., Blander, G., Tse, J.G., Krieger, M., Guarente, L., 2007. SIRT1 deacetylates and positively regulates the nuclear receptor LXR. Molecular cell 28, 91-106.

Liu, J., Ma, K.L., Zhang, Y., Wu, Y., Hu, Z.B., Lv, L.L., Tang, R.N., Liu, H., Ruan, X.Z., Liu, B.C., 2015. Activation of $\mathrm{mTORC1}$ disrupted LDL receptor pathway: a potential new mechanism for the progression of non-alcoholic fatty liver disease. The international journal of biochemistry \& cell biology 61, 8-19.

London, D.S., Beezhold, B., 2015. A phytochemical-rich diet may explain the absence of age-related decline in visual acuity of Amazonian hunter-gatherers in Ecuador. Nutrition Research 35, 107-117.

Lu, J., Hubner, K., Nanjee, M.N., Brinton, E.A., Mazer, N.A., 2014. An in-silico model of lipoprotein metabolism and kinetics for the evaluation of targets and biomarkers in the reverse cholesterol transport pathway. PLoS Comput Biol 10, e1003509.

Lu, Y., Feskens, E.J., Boer, J.M., Muller, M., 2010. The potential influence of genetic variants in genes along bile acid and bile metabolic pathway on blood cholesterol levels in the population. Atherosclerosis 210, 14-27.

Luthi-Carter, R., Taylor, D.M., Pallos, J., Lambert, E., Amore, A., Parker, A., Moffitt, H., Smith, D.L., Runne, H., Gokce, O., Kuhn, A., Xiang, Z., Maxwell, M.M., Reeves, S.A., Bates, G.P., Neri, C., Thompson, L.M., Marsh, J.L., Kazantsev, A.G., 2010. SIRT2 inhibition achieves neuroprotection by decreasing sterol biosynthesis. Proceedings of the National Academy of Sciences 107, 7927-7932.

Lv, Y.-B., Yin, Z.-X., Chei, C.-L., Qian, H.-Z., Kraus, V.B., Zhang, J., Brasher, M.S., Shi, X.-M., Matchar, D.B., Zeng, Y., 2015. Low-density lipoprotein cholesterol was inversely associated with 3-year all-cause mortality among Chinese oldest old: Data from the Chinese Longitudinal Healthy Longevity Survey. Atherosclerosis 239, 137-142.

Mahley, R.W., Rall, S.C., Jr., 2000. Apolipoprotein E: far more than a lipid transport protein. Annu Rev Genomics Hum Genet 1, 507-537.

Mahmoudi, M.J., Mahmoudi, M., Siassi, F., Shokri, F., Eshraghian, M.R., Zarnani, A.H., Chahardoli, R., Hedayat, M., Khoshnoodi, J., Nayeri, H., Rezaei, N., Saboor-Yaraghi, A.A., 2011. Lymphocyte cytotoxicity of oxLDL in patients with atherosclerosis. Iran J Immunol 8, 27-33.

Makino, S., Ikegami, S., Kume, A., Horiuchi, H., Sasaki, H., Orii, N., 2010. Reducing the risk of infection in the elderly by dietary intake of yoghurt fermented with Lactobacillus delbrueckii ssp. bulgaricus OLL1073R-1. Br J Nutr 104, 998-1006.

Makivuokko, H., Tiihonen, K., Tynkkynen, S., Paulin, L., Rautonen, N., 2010. The effect of age and non-steroidal anti-inflammatory drugs on human intestinal microbiota composition. $\mathrm{Br} J$ Nutr 103, 227-234.

Marciani, L., Cox, E.F., Hoad, C.L., Totman, J.J., Costigan, C., Singh, G., Shepherd, V., Chalkley, L., Robinson, M., Ison, R., Gowland, P.A., Spiller, R.C., 2013. Effects of various food ingredients on gall bladder emptying. Eur J Clin Nutr 67, 1182-1187.

Martín, B., Solanas-Barca, M., García-Otín, Á.L., Pampín, S., Cofán, M., Ros, E., Rodríguez-Rey, J.C., Pocoví, M., Civeira, F., 2010. An NPC1L1 gene promoter variant is associated with autosomal 
dominant hypercholesterolemia. Nutrition, Metabolism and Cardiovascular Diseases 20, 236-242.

Masson, C.J., Plat, J., Mensink, R.P., Namiot, A., Kisielewski, W., Namiot, Z., Füllekrug, J., Ehehalt, R., Glatz, J.F.C., Pelsers, M.M.A.L., 2010. Fatty Acid- and Cholesterol Transporter Protein Expression along the Human Intestinal Tract. PLoS ONE 5, e10380.

Mazein, A., Watterson, S., Hsieh, W.Y., Griffiths, W.J., Ghazal, P., 2013. A comprehensive machinereadable view of the mammalian cholesterol biosynthesis pathway. Biochem Pharmacol 86 , 56-66.

Mc Auley, M., Jones, J., Wilkinson, D., Kirkwood, T., 2005. Modelling Lipid Metabolism to Improve Healthy Ageing. BMC Bioinformatics 6, P21.

Mc Auley, M.T., Mooney, K.M., 2014. Lipid metabolism and hormonal interactions: impact on cardiovascular disease and healthy aging. Expert Review of Endocrinology \& Metabolism 9, 357-367.

Mc Auley, M.T., Mooney, K.M., 2015a. Computational systems biology for aging research. Interdisciplinary topics in gerontology 40, 35-48.

Mc Auley, M.T., Mooney, K.M., 2015b. Computationally Modeling Lipid Metabolism and Aging: A Mini-review. Computational and Structural Biotechnology Journal 13, 38-46.

Mc Auley, M.T., Mooney, K.M., Angell, P.J., Wilkinson, S.J., 2015. Mathematical modelling of metabolic regulation in aging. Metabolites 5, 232-251.

Mc Auley, M.T., Proctor, C., Corfe, B., Cuskelly, C., Mooney, K., 2013. Nutrition research and the impact of computational systems biology. J Comput Sci Syst Biol 6, 271-285.

Mc Auley, M.T., Wilkinson, D.J., Jones, J.J.L., Kirkwood, T.B.L., 2012. A whole-body mathematical model of cholesterol metabolism and its age-associated dysregulation. BMC Systems Biology 6, 130-130.

McAuley, M.T., Kenny, R.A., Kirkwood, T.B., Wilkinson, D.J., Jones, J.J., Miller, V.M., 2009. A mathematical model of aging-related and cortisol induced hippocampal dysfunction. BMC Neurosci 10, 26.

McCarthy, R.R., O'Gara, F., 2015. The impact of phytochemicals present in the diet on microbial signalling in the human gut. Journal of Functional Foods 14, 684-691.

McCaskie, P.A., Cadby, G., Hung, J., McQuillan, B.M., Chapman, C.M., Carter, K.W., Thompson, P.L., Palmer, L.J., Beilby, J.P., 2006. The C-480T hepatic lipase polymorphism is associated with HDL-C but not with risk of coronary heart disease. Clin Genet 70, 114-121.

Menotti, A., Blackburn, H., Seccareccia, F., Kromhout, D., Nissinen, A., Karyonen, M., Fidanza, F., Giampaoli, S., Buzina, R., Mohacek, I., Nedeljkovic, S., Aravanis, C., Dontas, A., 1998. Relationship of some risk factors with typical and atypical manifestations of coronary heart disease. Cardiology 89, 59-67.

Menotti, A., Kromhout, D., Blackburn, H., Jacobs, D., Lanti, M., 2004a. Forty-year mortality from cardiovascular diseases and all causes of death in the US Railroad cohort of the Seven Countries Study. Eur J Epidemiol 19, 417-424.

Menotti, A., Lanti, M., Kafatos, A., Nissinen, A., Dontas, A., Nedeljkovic, S., Kromhout, D., 2004b. The role of a baseline casual blood pressure measurement and of blood pressure changes in middle age in prediction of cardiovascular and all-cause mortality occurring late in life: a cross-cultural comparison among the European cohorts of the Seven Countries Study. J Hypertens 22, 1683-1690.

Messaoudi, M., Lalonde, R., Violle, N., Javelot, H., Desor, D., Nejdi, A., Bisson, J.F., Rougeot, C., Pichelin, M., Cazaubiel, M., Cazaubiel, J.M., 2011. Assessment of psychotropic-like properties of a probiotic formulation (Lactobacillus helveticus R0052 and Bifidobacterium longum R0175) in rats and human subjects. Br J Nutr 105, 755-764.

Millar, J.S., Lichtenstein, A.H., Cuchel, M., Dolnikowski, G.G., Hachey, D.L., Cohn, J.S., Schaefer, E.J., 1995. Impact of age on the metabolism of VLDL, IDL, and LDL apolipoprotein B-100 in men. Journal of lipid research 36, 1155-1167. 
Milman, S., Atzmon, G., Crandall, J., Barzilai, N., 2014. Phenotypes and Genotypes of High Density Lipoprotein Cholesterol in Exceptional Longevity. Current vascular pharmacology 12, 690 697.

Mishra, S., Somvanshi, P.R., Venkatesh, K., 2014. Control of cholesterol homeostasis by enterohepatic bile transport-the role of feedback mechanisms. RSC Advances 4, 58964-58975.

Mooney, K.M., Morgan, A.E., Mc Auley, M.T., 2016. Aging and computational systems biology. Wiley Interdisciplinary Reviews: Systems Biology and Medicine 8, 123-139.

Mueller, S., Saunier, K., Hanisch, C., Norin, E., Alm, L., Midtvedt, T., Cresci, A., Silvi, S., Orpianesi, C., Verdenelli, M.C., Clavel, T., Koebnick, C., Zunft, H.-J.F., Doré, J., Blaut, M., 2006. Differences in Fecal Microbiota in Different European Study Populations in Relation to Age, Gender, and Country: a Cross-Sectional Study. Applied and Environmental Microbiology 72, 1027-1033.

Muendlein, A., Leiherer, A., Saely, C.H., Rein, P., Zanolin, D., Kinz, E., Brandtner, E.-M., Fraunberger, P., Drexel, H., 2015. Common single nucleotide polymorphisms at the NPC1L1 gene locus significantly predict cardiovascular risk in coronary patients. Atherosclerosis 242, 340-345.

Muñoz-Barrios, S., Guzmán-Guzmán, I.P., Muñoz-Valle, J.F., Salgado-Bernabé, A.B., Salgado-Goytia, L., Parra-Rojas, I., 2012. Association of the Hindiii and S447X Polymorphisms in Lpl Gene with Hypertension and Type 2 Diabetes in Mexican Families. Disease markers 33, 313-320.

Murr, C., Grammer, T.B., Kleber, M.E., Meinitzer, A., Marz, W., Fuchs, D., 2015. Low serum tryptophan predicts higher mortality in cardiovascular disease. Eur J Clin Invest 45, 247-254.

Murtomäki, S., Tahvanainen, E., Antikainen, M., Tiret, L., Nicaud, V., Jansen, H., Ehnholm, C., Group, o.b.o.t.E.A.R.S., 1997. Hepatic Lipase Gene Polymorphisms Influence Plasma HDL Levels: Results From Finnish EARS Participants. Arteriosclerosis, Thrombosis, and Vascular Biology 17, 1879-1884.

Nagafuchi, S., Yamaji, T., Kawashima, A., Saito, Y., Takahashi, T., Yamamoto, T., Maruyama, M., Akatsu, H., 2015. Effects of a Formula Containing Two Types of Prebiotics, Bifidogenic Growth Stimulator and Galacto-oligosaccharide, and Fermented Milk Products on Intestinal Microbiota and Antibody Response to Influenza Vaccine in Elderly Patients: A Randomized Controlled Trial. Pharmaceuticals 8, 351-365.

Navarese, E.P., Kolodziejczak, M., Schulze, V., Gurbel, P.A., Tantry, U., Lin, Y., Brockmeyer, M., Kandzari, D.E., Kubica, J.M., D'Agostino, R.B., Sr., Kubica, J., Volpe, M., Agewall, S., Kereiakes, D.J., Kelm, M., 2015. Effects of Proprotein Convertase Subtilisin/Kexin Type 9 Antibodies in Adults With Hypercholesterolemia: A Systematic Review and Meta-analysis. Annals of internal medicine 163, 40-51.

Netea, M.G., Demacker, P.N., Kullberg, B.J., Boerman, O.C., Verschueren, I., Stalenhoef, A.F., van der Meer, J.W., 1996. Low-density lipoprotein receptor-deficient mice are protected against lethal endotoxemia and severe gram-negative infections. The Journal of clinical investigation 97, 1366-1372.

Norata, G.D., Banfi, C., Pirillo, A., Tremoli, E., Hamsten, A., Catapano, A.L., Eriksson, P., 2004. Oxidised-HDL3 induces the expression of PAI-1 in human endothelial cells. Role of p38MAPK activation and mRNA stabilization. Br J Haematol 127, 97-104.

O'Sullivan, O., Coakley, M., Lakshminarayanan, B., Conde, S., Claesson, M.J., Cusack, S., Fitzgerald, A.P., O'Toole, P.W., Stanton, C., Ross, R.P., 2013. Alterations in intestinal microbiota of elderly Irish subjects post-antibiotic therapy. J Antimicrob Chemother 68, 214-221.

Ohashi, R., Mu, H., Wang, X., Yao, Q., Chen, C., 2005. Reverse cholesterol transport and cholesterol efflux in atherosclerosis. QJM 98, 845-856.

Oner, O., Aslim, B., Aydas, S.B., 2014. Mechanisms of cholesterol-lowering effects of lactobacilli and bifidobacteria strains as potential probiotics with their bsh gene analysis. J Mol Microbiol Biotechnol 24, 12-18.

Paalvast, Y., Kuivenhoven, J.A., Groen, A.K., 2015. Evaluating computational models of cholesterol metabolism. Biochimica et Biophysica Acta (BBA) - Molecular and Cell Biology of Lipids 1851, 1360-1376. 
Parini, P., Angelin, B., Rudling, M., 1999. Cholesterol and lipoprotein metabolism in aging: reversal of hypercholesterolemia by growth hormone treatment in old rats. Arterioscler Thromb Vasc Biol 19, 832-839.

Park, S.-H., Kim, K.-A., Ahn, Y.-T., Jeong, J.-J., Huh, C.-S., Kim, D.-H., 2015. Comparative analysis of gut microbiota in elderly people of urbanized towns and longevity villages. BMC Microbiology $15,49$.

Parton, A., McGilligan, V., O’Kane, M., Baldrick, F.R., Watterson, S., 2015. Computational modelling of atherosclerosis. Briefings in Bioinformatics.

Patel, S., Shukla, R., Goyal, A., 2015. Probiotics in valorization of innate immunity across various animal models. Journal of Functional Foods 14, 549-561.

Peterson, T.R., Sengupta, S.S., Harris, T.E., Carmack, A.E., Kang, S.A., Balderas, E., Guertin, D.A., Madden, K.L., Carpenter, A.E., Finck, B.N., Sabatini, D.M., 2011. mTOR complex 1 regulates lipin 1 localization to control the SREBP pathway. Cell 146, 408-420.

Phillips, M.C., 2014. Apolipoprotein E isoforms and lipoprotein metabolism. IUBMB Life 66, 616-623.

Planavila, A., Iglesias, R., Giralt, M., Villarroya, F., 2011. Sirt1 acts in association with PPARalpha to protect the heart from hypertrophy, metabolic dysregulation, and inflammation. Cardiovascular research 90, 276-284.

Polisecki, E., Peter, I., Simon, J.S., Hegele, R.A., Robertson, M., Ford, I., Shepherd, J., Packard, C., Jukema, J.W., de Craen, A.J.M., Westendorp, R.G.J., Buckley, B.M., Schaefer, E.J., on behalf of the Prospective Study of Pravastatin in the Elderly at Risk, I., 2010. Genetic variation at the NPC1L1 gene locus, plasma lipoproteins, and heart disease risk in the elderly. Journal of lipid research 51, 1201-1207.

Popov, D., 2010. Endothelial cell dysfunction in hyperglycemia: Phenotypic change, intracellular signaling modification, ultrastructural alteration, and potential clinical outcomes. International Journal of Diabetes Mellitus 2, 189-195.

Puska, P., 1973. The North Karelia project: an attempt at community prevention of cardiovascular disease. WHO Chron 27, 55-58.

Puska, P., 2008. The North Karelia Project: 30 years successfully preventing chronic diseases. Diabetes Voice 53, 26-29.

Puska, P., Tuomilehto, J., Salonen, J., Neittaanmäki, L., Maki, J., Virtamo, J., Nissinen, A., Koskela, K., Takalo, T., 1979. Changes in coronary risk factors during comprehensive five-year community programme to control cardiovascular diseases (North Karelia project). British Medical Journal 2, 1173-1178.

Rader, D.J., Schaefer, J.R., Lohse, P., Ikewaki, K., Thomas, F., Harris, W.A., Zech, L.A., Dujovne, C.A., Brewer, H.B., Jr., 1993. Increased production of apolipoprotein A-I associated with elevated plasma levels of high-density lipoproteins, apolipoprotein A-I, and lipoprotein A-I in a patient with familial hyperalphalipoproteinemia. Metabolism 42, 1429-1434.

Rampelli, S., Candela, M., Turroni, S., Biagi, E., Collino, S., Franceschi, C., O'Toole, P.W., Brigidi, P., 2013. Functional metagenomic profiling of intestinal microbiome in extreme ageing. Aging (Albany NY) 5, 902-912.

Repa, J.J., Berge, K.E., Pomajzl, C., Richardson, J.A., Hobbs, H., Mangelsdorf, D.J., 2002. Regulation of ATP-binding Cassette Sterol Transporters ABCG5 and ABCG8 by the Liver X Receptors $\alpha$ and B. Journal of Biological Chemistry 277, 18793-18800.

Rhinn, H., Fujita, R., Qiang, L., Cheng, R., Lee, J.H., Abeliovich, A., 2013. Integrative genomics identifies APOE $\varepsilon 4$ effectors in Alzheimer's disease. Nature 500, 45-50.

Richard, C., Couture, P., Desroches, S., Benjannet, S., Seidah, N.G., Lichtenstein, A.H., Lamarche, B., 2012. Effect of the Mediterranean diet with and without weight loss on surrogate markers of cholesterol homeostasis in men with the metabolic syndrome. Br J Nutr 107, 705-711.

Ridaura, V.K., Faith, J.J., Rey, F.E., Cheng, J., Duncan, A.E., Kau, A.L., Griffin, N.W., Lombard, V., Henrissat, B., Bain, J.R., Muehlbauer, M.J., Ilkayeva, O., Semenkovich, C.F., Funai, K., Hayashi, D.K., Lyle, B.J., Martini, M.C., Ursell, L.K., Clemente, J.C., Van Treuren, W., Walters, W.A., 
Knight, R., Newgard, C.B., Heath, A.C., Gordon, J.I., 2013. Gut Microbiota from Twins Discordant for Obesity Modulate Metabolism in Mice. Science 341.

Rifai, L., Silver, M.A., 2015. A Review of the DASH Diet as an Optimal Dietary Plan for Symptomatic Heart Failure. Progress in Cardiovascular Diseases.

Ristow, M., Zarse, K., 2010. How increased oxidative stress promotes longevity and metabolic health: The concept of mitochondrial hormesis (mitohormesis). Exp Gerontol 45, 410-418.

Rosenfeld, M.E., Campbell, L.A., 2011. Pathogens and atherosclerosis: update on the potential contribution of multiple infectious organisms to the pathogenesis of atherosclerosis. Thromb Haemost 106, 858-867.

Ross, R., Masuda, J., Raines, E., Gown, A., Katsuda, S., Sasahara, M., Malden, L., Masuko, H., Sato, H., 1990. Localization of PDGF-B protein in macrophages in all phases of atherogenesis. Science $248,1009-1012$.

Salas-Salvadó, J., Bulló, M., Babio, N., Martínez-González, M.Á., Ibarrola-Jurado, N., Basora, J., Estruch, R., Covas, M.I., Corella, D., Arós, F., Ruiz-Gutiérrez, V., Ros, E., Investigators, f.t.P.S., 2011. Reduction in the Incidence of Type 2 Diabetes With the Mediterranean Diet: Results of the PREDIMED-Reus nutrition intervention randomized trial. Diabetes Care 34, 14-19.

Salemans, J.M., Nagengast, F.M., Tangerman, A., van Schaik, A., Hopman, W.P., de Haan, A.F., Jansen, J.B., 1993. Effect of ageing on postprandial conjugated and unconjugated serum bile acid levels in healthy subjects. Eur J Clin Invest 23, 192-198.

Sane, A.T., Sinnett, D., Delvin, E., Bendayan, M., Marcil, V., Menard, D., Beaulieu, J.F., Levy, E., 2006. Localization and role of NPC1L1 in cholesterol absorption in human intestine. Journal of lipid research 47, 2112-2120.

Saneei, P., Salehi-Abargouei, A., Esmaillzadeh, A., Azadbakht, L., 2014. Influence of Dietary Approaches to Stop Hypertension (DASH) diet on blood pressure: A systematic review and meta-analysis on randomized controlled trials. Nutrition, Metabolism and Cardiovascular Diseases 24, 1253-1261.

Santoro, A., Pini, E., Scurti, M., Palmas, G., Berendsen, A., Brzozowska, A., Pietruszka, B., Szczecinska, A., Cano, N., Meunier, N., de Groot, C.P.G.M., Feskens, E., Fairweather-Tait, S., Salvioli, S., Capri, M., Brigidi, P., Franceschi, C., Fabbri, C., Bertarelli, C., Izzi, M., Mazzocchi, M., Chardigny, J.M., Morio, B., Rossi, D., Notarfonso, M., O’Toole, P.W., Cashman, K., Carding, S.R., Nicoletti, C., Jacobs, D., Xipsiti, M., Fernandez, L., Wills, J., Irz, X., Kuosmanen, N., Gonos, E.S., Voutetakis, K., Salmon, M., Toussaint, O., Traill, B.W., Nocella, G., Caracciolo, B., Xu, W., Mikko, I., Tuure, T., Brummer, R., Kadi, F., Breton, S., Triomphe, M., Magario, G., Villani, F., Pancrazio, A., Teufner, B., Stocker, J., Echevarría, F.J., Iglesias, J.R., Smrž, F., Krejcirova, L., Koytsomitropoulou, E., Georgakidis, K., Yornuk, R., Ucar, C., Van Ommen, B., Bouwman, J., Collino, S., Jankovics, C., Losó, A., de Vos, W., Fuentes, S., Commelin, E., 2014. Combating inflammaging through a Mediterranean whole diet approach: The NU-AGE project's conceptual framework and design. Mechanisms of Ageing and Development 136-137, 3-13.

Satoh, A., Stein, L., Imai, S., 2011. The role of mammalian sirtuins in the regulation of metabolism, aging, and longevity. Handbook of experimental pharmacology 206, 125-162.

Savignac, H.M., Tramullas, M., Kiely, B., Dinan, T.G., Cryan, J.F., 2015. Bifidobacteria modulate cognitive processes in an anxious mouse strain. Behav Brain Res 287, 59-72.

Sayin, Sama I., Wahlström, A., Felin, J., Jäntti, S., Marschall, H.-U., Bamberg, K., Angelin, B., Hyötyläinen, T., Orešič, M., Bäckhed, F., 2013. Gut Microbiota Regulates Bile Acid Metabolism by Reducing the Levels of Tauro-beta-muricholic Acid, a Naturally Occurring FXR Antagonist. Cell metabolism 17, 225-235.

Schuijt, T.J., Lankelma, J.M., Scicluna, B.P., de Sousa e Melo, F., Roelofs, J.J.T.H., de Boer, J.D., Hoogendijk, A.J., de Beer, R., de Vos, A., Belzer, C., de Vos, W.M., van der Poll, T., Wiersinga, W.J., 2015. The gut microbiota plays a protective role in the host defence against pneumococcal pneumonia. Gut. 
Schulz, T.J., Zarse, K., Voigt, A., Urban, N., Birringer, M., Ristow, M., 2007. Glucose restriction extends Caenorhabditis elegans life span by inducing mitochondrial respiration and increasing oxidative stress. Cell metabolism 6, 280-293.

Schupf, N., Barral, S., Perls, T., Newman, A., Christensen, K., Thyagarajan, B., Province, M., Rossi, W.K., Mayeux, R., 2013. Apolipoprotein E and Familial Longevity. Neurobiology of aging 34, 1287-1291.

Shankaran, H., Resat, H., Wiley, H.S., 2007. Cell Surface Receptors for Signal Transduction and Ligand Transport: A Design Principles Study. PLoS Comput Biol 3, e101.

Shayganni, E., Bahmani, M., Asgary, S., Rafieian-Kopaei, M., 2015. Inflammaging and cardiovascular disease: Management by medicinal plants. Phytomedicine.

Shorten, P.R., Upreti, G.C., 2005. A mathematical model of fatty acid metabolism and VLDL assembly in human liver. Biochim Biophys Acta 1736, 94-108.

Simon, J.S., Karnoub, M.C., Devlin, D.J., Arreaza, M.G., Qiu, P., Monks, S.A., Severino, M.E., Deutsch, P., Palmisano, J., Sachs, A.B., Bayne, M.L., Plump, A.S., Schadt, E.E., 2005. Sequence variation in NPC1L1 and association with improved LDL-cholesterol lowering in response to ezetimibe treatment. Genomics 86, 648-656.

Sips, F.L., Tiemann, C.A., Oosterveer, M.H., Groen, A.K., Hilbers, P.A., van Riel, N.A., 2014. A computational model for the analysis of lipoprotein distributions in the mouse: translating FPLC profiles to lipoprotein metabolism. PLoS Comput Biol 10, e1003579.

Soroka, C.J., Boyer, J.L., 2014. Biosynthesis and trafficking of the bile salt export pump, BSEP: therapeutic implications of BSEP mutations. Mol Aspects Med 37, 3-14.

Soumyarani, V.S., Jayakumari, N., 2012. Oxidatively modified high density lipoprotein promotes inflammatory response in human monocytes-macrophages by enhanced production of ROS, TNF-alpha, MMP-9, and MMP-2. Mol Cell Biochem 366, 277-285.

Spady, D.K., Turley, S.D., Dietschy, J.M., 1985. Receptor-independent low density lipoprotein transport in the rat in vivo. Quantitation, characterization, and metabolic consequences. The Journal of clinical investigation 76, 1113-1122.

Steenbergen, L., Sellaro, R., van Hemert, S., Bosch, J.A., Colzato, L.S., 2015. A randomized controlled trial to test the effect of multispecies probiotics on cognitive reactivity to sad mood. Brain, Behavior, and Immunity 48, 258-264.

Stewart, T.M., Bhapkar, M., Das, S., Galan, K., Martin, C.K., McAdams, L., Pieper, C., Redman, L., Roberts, S., Stein, R.I., Rochon, J., Williamson, D.A., 2013. Comprehensive Assessment of Long-term Effects of Reducing Intake of Energy Phase 2 (CALERIE Phase 2) screening and recruitment: methods and results. Contemp Clin Trials 34, 10-20.

Stitziel, N.O., Won, H.-H., Morrison, A.C., Peloso, G.M., Do, R., Lange, L.A., Fontanillas, P., Gupta, N., Duga, S., Goel, A., 2014. Inactivating mutations in NPC1L1 and protection from coronary heart disease. The New England journal of medicine 371, 2072-2082.

Streppel, M.T., Ocke, M.C., Boshuizen, H.C., Kok, F.J., Kromhout, D., 2008. Dietary fiber intake in relation to coronary heart disease and all-cause mortality over 40 y: the Zutphen Study. Am J Clin Nutr 88, 1119-1125.

Tancharoenrat, P., Ravindran, V., Zaefarian, F., Ravindran, G., 2014. Digestion of fat and fatty acids along the gastrointestinal tract of broiler chickens. Poultry Science 93, 371-379.

Tao, R., Xiong, X., DePinho, R.A., Deng, C.X., Dong, X.C., 2013. Hepatic SREBP-2 and cholesterol biosynthesis are regulated by FoxO3 and Sirt6. Journal of lipid research 54, 2745-2753.

Taormina, G., Mirisola, M.G., 2014. Calorie Restriction in Mammals and Simple Model Organisms. BioMed Research International 2014, 10.

Tassi, S., Carta, S., Vene, R., Delfino, L., Ciriolo, M.R., Rubartelli, A., 2009. Pathogen-induced interleukin-1beta processing and secretion is regulated by a biphasic redox response. J Immunol 183, 1456-1462. 
Tikellis, G., Sun, C., Gorin, M.B., Klein, R., Klein, B.E., Larsen, E.K., Siscovick, D.S., Hubbard, L.D., Wong, T.Y., 2007. Apolipoprotein e gene and age-related maculopathy in older individuals: the cardiovascular health study. Arch Ophthalmol 125, 68-73.

Trichopoulou, A., Lagiou, P., 1997. Healthy traditional Mediterranean diet: an expression of culture, history, and lifestyle. Nutr Rev 55, 383-389.

Uchida, K., Satoh, T., Chikai, T., Takase, H., Nomura, Y., Nakao, H., Takeuchi, N., 1996. Influence of cholesterol feeding on bile acid metabolism in young and aged germ-free rats. Jpn J Pharmacol 71, 113-118.

Vartiainen, E., Laatikainen, T., Peltonen, M., Juolevi, A., Mannisto, S., Sundvall, J., Jousilahti, P., Salomaa, V., Valsta, L., Puska, P., 2010. Thirty-five-year trends in cardiovascular risk factors in Finland. Int J Epidemiol 39, 504-518.

Veniant, M.M., Zlot, C.H., Walzem, R.L., Pierotti, V., Driscoll, R., Dichek, D., Herz, J., Young, S.G., 1998. Lipoprotein clearance mechanisms in LDL receptor-deficient "Apo-B48-only" and "Apo-B100-only" mice. The Journal of clinical investigation 102, 1559-1568.

Vogiatzi, G., Tousoulis, D., Stefanadis, C., 2009. The role of oxidative stress in atherosclerosis. Hellenic J Cardiol 50, 402-409.

Wang, B.T., Ducker, G.S., Barczak, A.J., Barbeau, R., Erle, D.J., Shokat, K.M., 2011. The mammalian target of rapamycin regulates cholesterol biosynthetic gene expression and exhibits a rapamycin-resistant transcriptional profile. Proc Natl Acad Sci U S A 108, 15201-15206.

Wang, F., Yu, T., Huang, G., Cai, D., Liang, X., Su, H., Zhu, Z., Li, D., Yang, Y., Shen, P., Mao, R., Yu, L., Zhao, M., Li, Q., 2015. Gut Microbiota Community and Its Assembly Associated with Age and Diet in Chinese Centenarians. J Microbiol Biotechnol 25, 1195-1204.

Wang, H.H., Patel, S.B., Carey, M.C., Wang, D.Q.H., 2007. Quantifying Anomalous Intestinal Sterol Uptake, Lymphatic Transport, and Biliary Secretion in Abcg8(-/-) Mice. Hepatology (Baltimore, Md.) 45, 998-1006.

Wang, J., Qiang, H., Chen, D., Zhang, C., Zhuang, Y., 2002. CETP gene mutation (D442G) increases low-density lipoprotein particle size in patients with coronary heart disease. Clin Chim Acta 322, 85-90.

Wang, J.C., Bennett, M., 2012. Aging and Atherosclerosis: Mechanisms, Functional Consequences, and Potential Therapeutics for Cellular Senescence. Circulation Research 111, 245-259.

Wang, Y., Ji, L., Jiang, R., Zheng, L., Liu, D., 2014. Oxidized high-density lipoprotein induces the proliferation and migration of vascular smooth muscle cells by promoting the production of ROS. J Atheroscler Thromb 21, 204-216.

Watterson, S., Guerriero, M.L., Blanc, M., Mazein, A., Loewe, L., Robertson, K.A., Gibbs, H., Shui, G., Wenk, M.R., Hillston, J., Ghazal, P., 2013. A model of flux regulation in the cholesterol biosynthesis pathway: Immune mediated graduated flux reduction versus statin-like led stepped flux reduction. Biochimie 95, 613-621.

Wattis, J.A., O'Malley, B., Blackburn, H., Pickersgill, L., Panovska, J., Byrne, H.M., Jackson, K.G., 2008. Mathematical model for low density lipoprotein (LDL) endocytosis by hepatocytes. Bull Math Biol 70, 2303-2333.

Wei, D., Tao, R., Zhang, Y., White, M.F., Dong, X.C., 2011. Feedback regulation of hepatic gluconeogenesis through modulation of SHP/NrOb2 gene expression by Sirt1 and FoxO1. American journal of physiology. Endocrinology and metabolism 300, E312-320.

Westerterp, M., van der Hoogt, C.C., de Haan, W., Offerman, E.H., Dallinga-Thie, G.M., Jukema, J.W., Havekes, L.M., Rensen, P.C.N., 2006. Cholesteryl Ester Transfer Protein Decreases HighDensity Lipoprotein and Severely Aggravates Atherosclerosis in APOE*3-Leiden Mice. Arteriosclerosis, Thrombosis, and Vascular Biology 26, 2552-2559.

WHO, 2015. Life expectancy data by country.

Wikgren, M., Karlsson, T., Nilbrink, T., Nordfjall, K., Hultdin, J., Sleegers, K., Van Broeckhoven, C., Nyberg, L., Roos, G., Nilsson, L.G., Adolfsson, R., Norrback, K.F., 2012. APOE epsilon4 is 
1691

1692

1693

1694

1695

1696

1697

1698

1699

1700

1701

1702

1703

1704

1705

1706

1707

associated with longer telomeres, and longer telomeres among epsilon4 carriers predicts worse episodic memory. Neurobiol Aging 33, 335-344.

Wilson, P.W., Anderson, K.M., Harris, T., Kannel, W.B., Castelli, W.P., 1994. Determinants of change in total cholesterol and HDL-C with age: the Framingham Study. Journal of gerontology 49, M252-257.

Woodside, J.V., McGrath, A.J., Lyner, N., McKinley, M.C., 2015. Carotenoids and health in older people. Maturitas 80, 63-68.

Yang, D., Elner, S.G., Bian, Z.-M., Till, G.O., Petty, H.R., Elner, V.M., 2007. Pro-inflammatory Cytokines Increase Reactive Oxygen Species through Mitochondria and NADPH Oxidase in Cultured RPE Cells. Experimental eye research 85, 462-472.

Zende, P.D., Bankar, M.P., Kamble, P.S., Momin, A.A., 2013. Apolipoprotein e gene polymorphism and its effect on plasma lipids in arteriosclerosis. J Clin Diagn Res 7, 2149-2152.

Zhong, S., Sharp, D.S., Grove, J.S., Bruce, C., Yano, K., Curb, J.D., Tall, A.R., 1996. Increased coronary heart disease in Japanese-American men with mutation in the cholesteryl ester transfer protein gene despite increased HDL levels. The Journal of clinical investigation 97, $2917-$ 2923. 